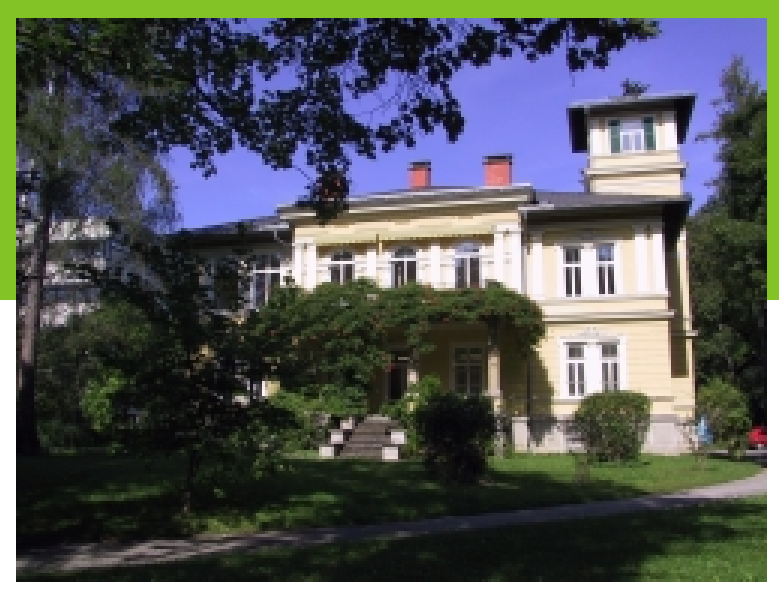

\title{
Spatial consumption-production structure and mobility related emissions
}

\author{
Olivia Koland \\ Birgit Friedl \\ Karl Steininger \\ Brigitte Gebetsroither
}

Austrian Academy of Sciences (Global Change Program) and Austrian National Bank (Jubiläumsfonds)
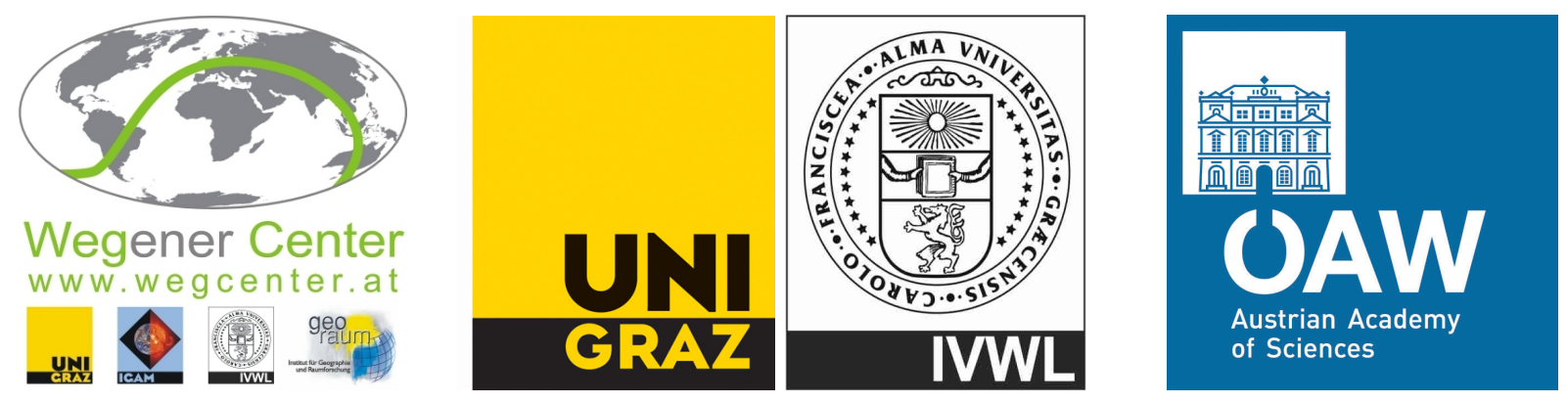
The Wegener Center for Climate and Global Change combines as an interdisciplinary, internationally oriented research center the competences of the University of Graz in the research area "Climate, Environmental and Global Change“. It brings together, in a dedicated building close to the University central campus, research teams and scientists from fields such as geo- and climate physics, meteorology, economics, geography, and regional sciences. At the same time close links exist and are further developed with many cooperation partners, both nationally and internationally. The research interests extend from monitoring, analysis, modeling and prediction of climate and environmental change via climate impact research to the analysis of the human dimensions of these changes, i.e, the role of humans in causing and being effected by climate and environmental change as well as in adaptation and mitigation. The director of the center, hosting about 35 researchers, is the geophysicist Gottfried Kirchengast, the lead partner and deputy director is the economist Karl Steininger. (more informationen at www.wegcenter.at)

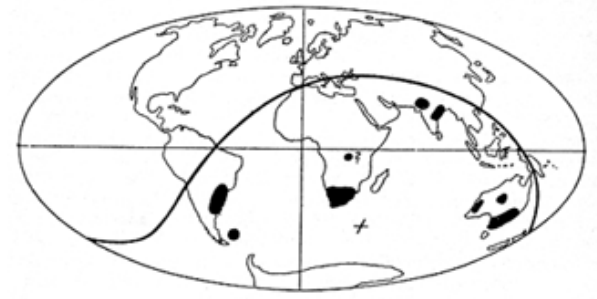

\begin{abstract}
Alfred Wegener (1880-1930), after whom the Wegener Center is named, was founding holder of the University of Graz Geophysics Chair (19241930 ) and was in his work in the fields of geophysics, meteorology, and climatology a brilliant, interdisciplinary thinking and acting scientist and scholar, far ahead of his time with this style. The way of his ground-breaking research on continental drift is a shining role model - his sketch on the relationship of the continents based on traces of an ice age about 300 million years ago (left) as basis for the Wegener Center Logo is thus a continuous encouragement to explore equally innovative scientific ways: ways emerge in that we go them (Motto of the Wegener Center).
\end{abstract}

\author{
Austrian Academy of Sciences Press \\ P.O.Box 471, Postgasse 7 • A-1011 Vienna, Austria \\ (C) 2008 All Rights Reserved. \\ Selected use of individual figures, tables or parts of text is permitted \\ for non-commercial purposes, provided this report is correctly and \\ clearly cited as the source. Publisher contact for any interests \\ beyond such use: verlag@oeaw.ac.at.
}

ISBN Online: 978-3-7001-3970-6

March 2008

Contact: Dr. Birgit Friedl

birgit.friedl@uni-graz.at

Wegener Center for Climate and Global Change

University of Graz

Leechgasse 25

A-8010 Graz, Austria

www.wegcenter.at 


\section{SPACON+}

\section{Spatial consumption-production structure and mobility related emissions}

Olivia Koland $^{1}$, Birgit Friedl ${ }^{1,2}$, Karl Steininger ${ }^{1,2}$, Brigitte Gebetsroither ${ }^{1}$

1 Wegener Center for Climate and Global Change, University of Graz, Leechgasse 25, $8010 \mathrm{Graz}$

2 Department of Economics, University of Graz, Universitätsstraße 15, 8010 Graz

March 2008

Financial support by the Austrian Academy of Sciences / Global Change Programme (project SPACON+) and by the OeNB, Jubiläumsfonds (project TranSustSpace, project no. 11502) is kindly acknowledged. 



\section{Summary}

While transport services are crucial to economic activities, the transport sector in its current shape is also connected to a range of substantial detrimental environmental impacts. We thus seek to enhance the modelling of transport demand and its environmental effects by developing a spatial Computable General Equilibrium model to evaluate transport and spatial planning instruments. Our model is of the core-periphery type, in which residents are mobile between an urban core and its hinterland. Migration is linked to shifts in pollution levels, caused by residents' mobility patterns, as well as regional differences in housing prices and in the variety of consumption goods. Building on New Economic Geography forces, we explain how urban sprawl affects settlement structures via a circular linkage of spatial environmental quality and mobility patterns. The empirical analysis aims to investigate the potential of using cordon pricing and spatial planning to improve the environment across both regions.

Both instruments induce adjustments in settlement structures and commuting behaviour, although in different ways. Cordon pricing acts as strengthening the weight of the region which is depopulated by urban sprawl (in our model, the centre). In contrast, spatial planning aimed at fostering dense living structures in the hinterland acts in a different way to reduce urban sprawl: Housing prices in the hinterland rise and supply a disincentive to resettle to the peripheral region.

The residential relocations induced by these policies lead to diverse environmental impacts, given that transport flows have varying environmental impacts. Generally speaking, the environmental impacts per trip are highest for interregional commuters (having both a high car dependency and long distances) and lowest for trips within the centre (due to a high share of public transport and short distances). For local pollutants, such as $\mathrm{PM}_{10}$, the pricing policy is connected to favorable emission reductions in both regions, whereas the hinterland planning measure has ambiguous results from an environmental perspective (with an improvement for the centre, but a degradation for the hinterland). When combining the effects on $\mathrm{CO}_{2}$ and $\mathrm{PM}_{10}$, cordon pricing and spatial planning lead to desirable effects for the overall region. 


\section{Kurzfassung}

Während Transportdienstleistungen essentiell für ökonomische Aktivitäten sind, trägt der Verkehr in seiner momentanen Form zu substantiellen negativen Umweltwirkungen bei. Ziel der vorliegenden Studie ist daher, die Modellierung der klimarelevanten Verkehrsnachfrage $\mathrm{zu}$ verbessern, indem ein räumliches Angewandtes Gleichgewichtsmodell zur Beurteilung von Verkehrs- und Raumplanungspolitik entwickelt wird. Das Modell basiert auf dem KernPeripherie-Modell, in dem die Bewohner zwischen einem urbanen Zentrum und einer Umlandregion mobil sind. Die Migration zwischen den Regionen wird durch Veränderungen in der Umweltqualität, verursacht durch das Mobilitätsverhalten der Bewohner, sowie durch regionale Unterschiede in Bezug auf Wohnpreise und Produktvielfalt beeinflusst. Basierend auf den Kräften der Neuen Ökonomischen Geographie wird erklärt, wie die Zersiedelung über eine zirkuläre Verkettung von räumlicher Umweltqualität und Mobilitätsverhalten die Siedlungsstruktur beeinflusst. In der empirischen Analyse wird das Potential von Cordon Pricing und Raumplanung zur Verbesserung der Umweltqualität in beiden Regionen untersucht.

Beide Instrumente führen $\mathrm{zu}$ Anpassungen in der Siedlungsstruktur und im Pendlerverhalten, jedoch in unterschiedlicher Art und Weise. Cordon Pricing verstärkt die Position jener Region, die durch eine Abwanderung von Bewohnern durch Zersiedelung charakterisiert ist (in unserem Modell das Zentrum). Im Unterschied dazu führen raumplanerische Maßnahmen mit dem Ziel einer verdichteten Siedlungsstruktur dazu, dass die Wohnpreise im Umland steigen und einen negativen Anreiz für das Umsiedeln in das Umland bieten.

Die durch diese Maßnahmen induzierte Veränderung des Wohnorts führt zu unterschiedlichen Umweltwirkungen aufgrund der Annahme, dass die Transportströme mit unterschiedlichen Umweltwirkungen verbunden sind. Im Allgemeinen sind die Umweltwirkungen pro Weg am höchsten für Pendler zwischen den Regionen (aufgrund hoher Autoabhängigkeit und langer Distanzen) und am niedrigsten innerhalb des Zentrums. Lokal schädliche Emissionen, wie $\mathrm{PM}_{10}$, werden durch Cordon Pricing in beiden Regionen verringert, während raumplanerische Maßnahmen zwar eine Verbesserung der Umweltqualität im Zentrum aber eine Verschlechterung im Umland bewirken. Bei einer gemeinsamen Betrachtung der Wirkungen auf $\mathrm{CO}_{2}$ und $\mathrm{PM}_{10}$ zeigt sich, dass Cordon Pricing und Raumplanung (Verdichtung der Siedlungsstruktur) zu erwünschten Umwelteffekten für die Gesamtregion führen. 


\section{Outline}

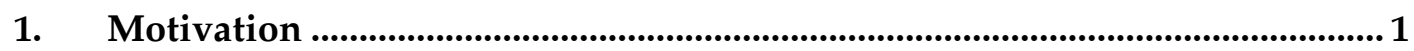

2. The theoretical model for passenger transport and the environment........... 3

2.1. An overview of New Economic Geography models ......................................... 3

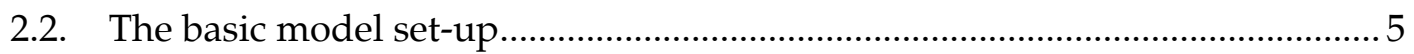

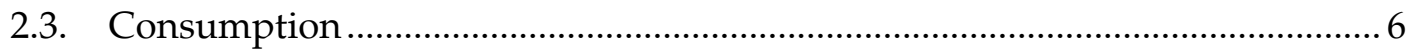

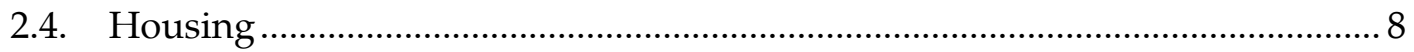

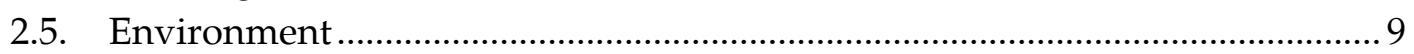

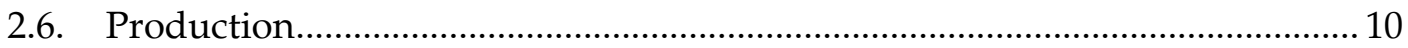

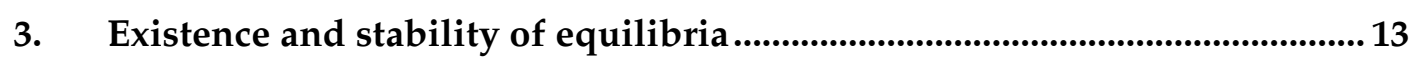

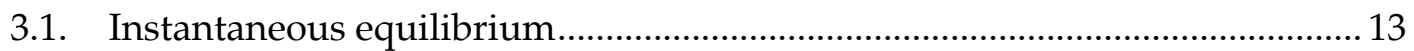

3.2. The price index effect and the home market effect ........................................ 14

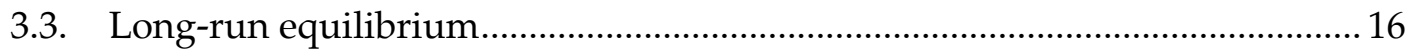

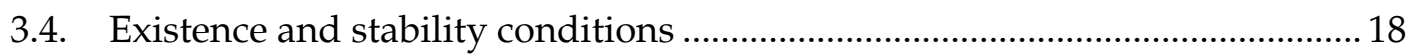

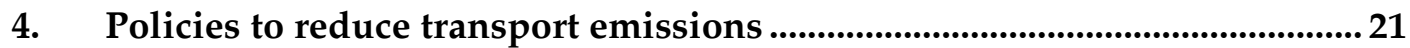

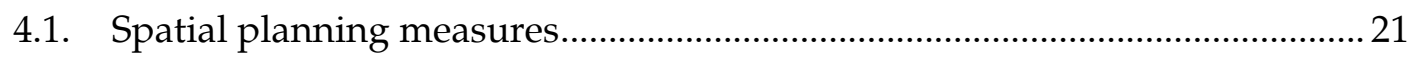

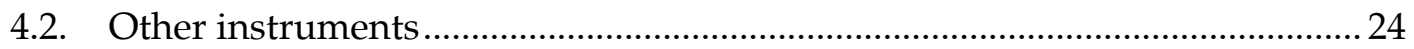

4.3. Fiscal instruments / pricing policies............................................................... 25

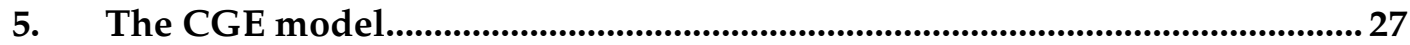

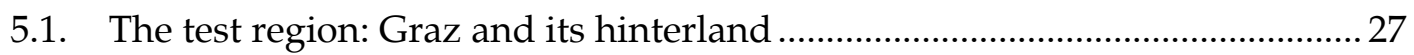

5.2. Environmental impacts from passenger transport ........................................29

5.3. The reference specification and the baseline scenario ..................................... 31

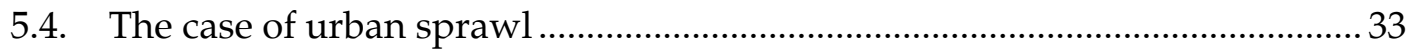

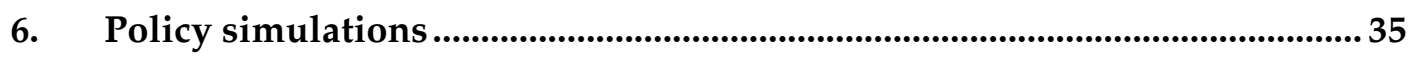

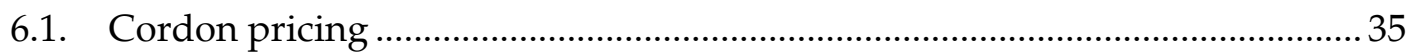

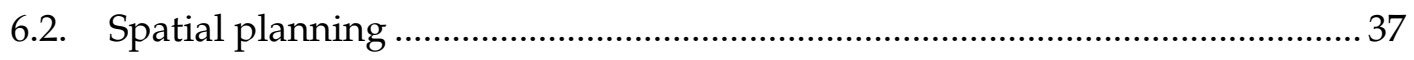

6.3. Effects on location of residence and commuting............................................... 39

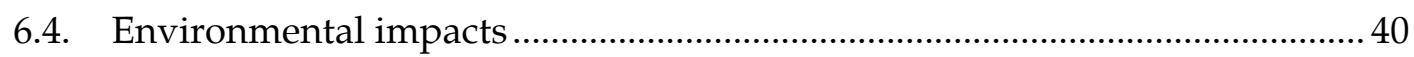

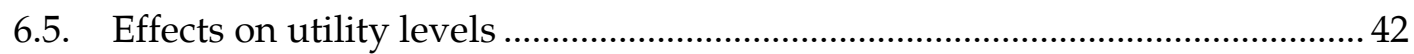

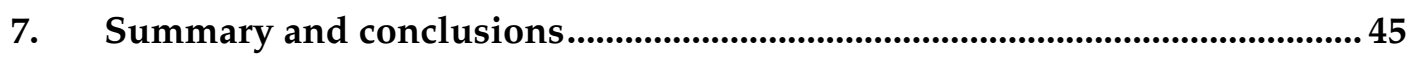

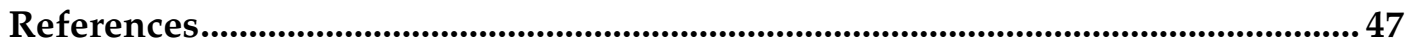

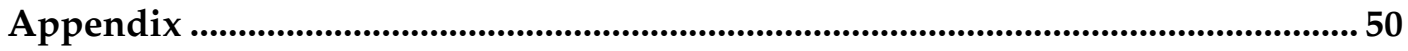





\section{Motivation}

While transport services are crucial to economic activities, the transport sector in its current shape is also connected to a range of substantial detrimental impacts. Most importantly for climate change, mobility activities currently trigger the fastest increasing segment in fossil fuel emissions. While total Austrian $\mathrm{CO}_{2}$ emissions increased by $18.1 \%$ between 1990 and 2005, emissions from transport increased by 91.6\% over this period (UBA, 2007). If Austria is to comply with its commitments within the European Union with respect to the Kyoto agreement, effective measures need to be prepared and implemented in due time. Similar demands for transport reorganisation arise from current noise and health impacts mainly felt within urban areas, which give an additional incentive for climate relevant transport improvements.

Though public transport infrastructure is available to address these problems, often settlement structures are too dispersed. The point is that transport flows are crucially interlinked with economic activity levels in the production and household sectors. In doing so, transportation interacts with urban development via real income effects, housing demand and mode choice. In particular, transport demand depends on the spatial organisation of an economy via distances and modal split which differs across locations. For instance, environmental pressures (pollution) or high housing prices in urban areas can trigger increased transport demand in certain peri-urban areas. On the other hand, availability of transport infrastructure can attract production activities or housing. This in turn explains how emission levels are dependent on settlement structures via the mobility patterns they induce. The mutual linkage of transport and economic activity is a clear conclusion from the now advanced New Economic Geography (NEG) literature, mainly drawing on theoretical and stylised models so far (for a comprehensive survey see Fujita et al., 1999; Baldwin et al., 2003).

In this report, we seek to enhance climate change relevant transport consumption modelling with respect to the spatially explicit extension of transport oriented economic computable general equilibrium (CGE) analysis. The issue we address is the suburbanisation of central areas and its linkages to commuting behaviour and environmental concerns. We do so by developing a two-region model building on (i) the theoretical NEG modelling advances and (ii) the spatially explicit extension of CGE. We start from the assumption that urban sprawl is driven by a declining quality of life in cities which is reinforced by the rising awareness of health impacts. We furthermore assume that it is the intensity of consumers' mobility trends which affects the local level of environmental quality. We then investigate 
how environmental effects in urban areas caused by transportation interact with other forces involved. Thus, migration is driven by differences in local environmental quality but also by differences in agglomeration economies, by shifts in housing prices and the level of commuting costs. Hereby, the levels of real income and environmental quality are endogenous variables determining the long run allocation of economic activities across the two regions.

To succeed in modelling spatially explicit at a sufficient level of detail the spatial CGE model is developed for one Austrian test area (Graz basin). We experience a clear trend towards urban sprawl in Austria, which is a result of changes in lifestyles and a rising per capita income, together with a high degree of motorisation and accessibility by road in the hinterland. What we observe is a rising demand for housing space, preferably near green belts with a high recreation value (OECD, 2005). The greater Graz region is characterized by increasingly dispersed settlement structures and, over the last decade, by a very dynamic development, with substantial detrimental effects in the transport sector (e.g. respiratory illnesses triggered by particulate matter emitted or re-circulated by transport, regular collapses of traffic flows in rush hours, noise effects).

In this manner we evaluate transport policy measures, with a focus on economic instruments for emission reduction and on spatial restructuring measures. Traditional climate policy addresses short term emission reduction objectives. With respect to transport, however, long-term choices in land-use and choices in transport are mutually dependent. Any given pattern of activity location induces a specific trip pattern, and, reversely, the location choice for each activity is dependent on the transport system and the opportunities it offers, since it is the transport system which defines the cost associated with all future activities at any specific location. Thus, also more general land use and transport instruments, such as public housing construction subsidies or variable car transport charges do have an influence on location decisions for firm production and housing. Such policies will therefore be investigated as well.

This report is structured as follows. Section 2 reports on the theoretical model including a literature review, while the existence and stability of equilibria is discussed in Section 3. Then, a review of suitable policy measures is given in Section 4. In Section 5 the theoretical model is implemented in a CGE format. Section 6 deals with the implementation of two policy measures, a congestion charge and a spatial planning instrument, into the CGE model. Then we outline the effects of these policies on urban residential distribution and commuting flows, on environmental quality and utility levels. Section 7 summarizes the results and concludes. 


\section{The theoretical model for passenger transport and the environment}

\subsection{An overview of New Economic Geography models}

This section presents an overview of existing two-region models which are based in New Economic Geography (NEG). The majority of them are extensions of the canonical core-periphery (CP) model (Krugman, 1991; Fujita et al., 1999; Baldwin et al., 2003), others start from the standard monocentric-city model (Alonso, 1964). In particular the $\mathrm{CP}$ modelling approach of Krugman has been modified along several lines (Ottaviano and Puga, 1998; Eckey and Kosfeld, 2004; Fujita and Mori, 2005).

The standard CP model contains the analytical essence of the NEG. It shows how the interactions between transport costs, increasing returns at firm level and factor mobility endogenously determine the extent of regional specialisation through simultaneous location choices of firms and labour. Hereby, the emphasis is on the firm's location decision. A second important point is that the CP model focuses on the alteration of transport costs to explain agglomeration patterns. However, in order to understand regional differences in population density, additional forces such as housing scarcity or urban pollution problems are to be included.

The consideration of non-tradable services in the NEG goes back to Helpman (1998), who replaces the standard agricultural sector with housing services. Residents are mobile, but they live and work in the same place. While in the standard NEG model dispersion is driven by region-specific demands by farmers, who own the homogenous product, in this model it is region-specific supplies (of homogenous housing) that act as a dispersion force. Helpman finds that agglomeration is more likely to occur when (interregional) transport costs are higher, which contradicts Krugman's result that falling transport costs lead to regional divergence.

All three sectors (agriculture, manufacturing, housing) are taken into consideration by Suedekum (2006) and Pflueger and Suedekum (2006). Suedekum's (2006) model implies that the true costs of living may be higher in the centre region, contradicting standard $\mathrm{CP}$ model predicitions. He builds on the integration of housing scarcity as a main determinant of regional price differentials. By contrast, Pflueger and Suedekum (2006) investigate the welfare effects of agglomeration and efficiency arguments for policy invention. Their main contribution is in finding an analytically precise way to disentangle the net pecuniary externality with mobile 
firms in the monopolistically competitive sector. What these two papers share, however, is the assumption of housing as a non-traded and non-produced consumption good (as in Helpman, 1998). As a result, there is no differentiation between the place of work and residence.

A number of papers (e.g. Tabuchi, 1998; Murata and Thisse, 2005) add urban structures to the NEG such that households face a trade-off between transport costs, space and amenity. Thereby, Murata and Thisse (2005) aim to unify the work of Helpman (1998) and Tabuchi (1998). The regional specification of these models is based on the monocentric residential model (Alonso, 1964), where workers live around a central business district and commute to it. With two regions of this type, these models do allow for the interplay between transport costs for interregional commodity supply and urban costs, i.e. workers' intraregional commuting costs and housing costs, in a spatial economy. Yet, by this means, they abstract from interregional commuting. A similar approach is developed by Tabuchi and Thisse (2006), who use the model developed by Ottaviano et al. (2002) (as an alternative to Krugman's (1991) set up) and who then extend their basic model to two sectors to study regional specialisation and urban hierarchy.

Regarding environmental concerns, Quaas and Lange (2007) extend the canonical CP model to include local environmental pollution, which is linked to production and thus to a concentration of skilled labour. Urban environmental problems act as a dispersing force, because they make agglomerations less favourable (producerconsumer externalities). In comparison to Krugman's results, their model can explain a third and more realistic type of equilibrium, i.e. a stable asymmetric and incomplete agglomeration of skilled workers in one of the two regions. Note that the occurring externalities in Quaas and Lange are of the producer-consumer type typically found in environmentally oriented models (see also e.g. Verhoef and Nijkamp, 2002; Arnott et al., 2004; Marrewijk, 2005; Yoshino, 2004). By contrast, an urban general equilibrium model with pollution from commuting was developed by Verhoef and Nijkamp (2003), yet this was accomplished in a monocentric city setup. Eppink and Withagen (2006) extend Krugman's CP model by the local level of biodiversity which is a function of two types of species with different extinction risks.

Drawing on these lines of work, we propose a simple model of economic geography to analyse the main determinants of urban sprawl and to address efficiency arguments for policy intervention. The framework is based on various modifications of Krugman's (1991) core-periphery model, whereby two extensions are particularly important: (i) the incorporation of urban features (housing market, commuting) into the NEG framework (Helpman, 1998; Tabuchi, 1998; Murata and 
Thisse, 2005; Tabuchi and Thisse, 2006), and (ii) the consideration of environmental aspects within a NEG framework (Yoshino, 2004; Quaas and Lange, 2007). More specifically, approaching from one side we extend Suedekum's (2006) framework to include environmental quality, thereby following Quaas and Lange (2007) and Eppink and Withagen (2006). Contrary to typical environmentally-oriented models (e.g. Marrewijk, 2005; Yoshino, 2004; Quaas and Lange, 2007) that handle producer-consumer externalities we assume pollution to be caused by commuting residents only, i.e. the intensity of mobility trends (expressed by the dimension of urban sprawl) is affecting the level of environmental quality. Approaching from the opposite direction, we introduce a housing market into the model by Quaas and Lange (2007), thereby following Suedekum (2006). An additional extension is that we let housing be traded at a cost in order to model interregional commuting. Hence, while in the CP model agglomeration is slowed down only by transport costs, we integrate other forces such as varying property prices and negative environmental impacts due to unfavourable mobility behaviour. This implies a more realistic assumption of redispersion of economic activity. While the NEG has dealt mainly with firms' location of production, the present study thus focuses on consumers' decisions to understand regional differences in population density.

In this endeavour, we assume that mobile consumers choose either of the two regions to live and work depending on what benefit the location offers in terms of environmental quality, housing and variety in consumption goods. Residents purchase differentiated products in both regions, whereby "imported" goods are costly to transport. In addition, residents pay commuting costs if the location of residence differs from the place of work (interregional commuting). In the empirical part of this report, we set up a stylized centre/surroundings model where both regions are perfectly identical except for environmental quality. We then proceed to evaluate policy measures, with a focus on economic instruments for emission reduction and on spatial restructuring measures.

\subsection{The basic model set-up}

We model an economy consisting of two regions, an urban core and its hinterland, which we will distinguish by an asterisk (*), and two sectors of production. First, a variety of manufacturing goods is produced under internal increasing returns to scale by labour and capital in a monopolistically competitive market. Second, the housing sector operates under perfect competition by use of labour so that $p_{H}=w_{H}$ and $p_{H}^{*}=w_{H}^{*}$. Capital is equally owned by all manufacturing workers. 
There are three (sector-specific) factors of production: While labour used in the housing production $L_{H}$ is immobile and equally distributed between core and hinterland, manufacturing workers $L_{M}$ are interregionally mobile, thereby determining a specific settlement structure. Moreover, capital $K_{M}$ is freely mobile across regions. We choose units for the supply of manufacturing workers $\bar{L}_{M}=L_{M}+L_{M}^{*}=\alpha$ and for housing producers $L_{H}=L_{H}^{*}=(1-\alpha) / 2$, which yields $\bar{L}_{H}=1-\alpha$. In addition, $L=L_{M}+L_{H}$ and $\bar{L}=\bar{L}_{M}+\bar{L}_{H}$, and total capital supply is $\bar{K}_{M}=K_{M}+K_{M}^{*}$.

\subsection{Consumption}

We assume that local environmental quality $Q$ is an essential component of consumers' welfare. Its level depends on the environmental impact of the number of commuters and non-commuters in each region. The share of commuters in the workforce per region is given by $s$ and $s^{*}$. The according damage function $D(s)$, $D(s) \leq 0$, will be described below. For the moment, let $D(s)$ affect the level of environmental quality as follows, implying a decrease in environmental quality with rising damage:

$Q=e^{D(s)}$ and $Q^{*}=e^{D\left(s^{*}\right)}$

All workers are final consumers and share the same preferences on $Q$, the composite manufacturing good $M$ and housing $H$ :

$U(M, H, Q)=M^{\alpha}\left(H_{c}^{\beta} H_{h}^{1-\beta}\right)^{1-\alpha}+\delta Q \quad 0 \leq \alpha \leq 1 ; 0<\beta<1, \beta \neq 0.5$

The notation is for the centre region with expressions identical for the hinterland. Parameter $\beta$ indicates the preference for commuting, with $\beta=1$ indicating full aversion to commuting. Parameter $\delta \geq 0$ expresses the intensity of environmental preferences. To model how utility increases via consumers' love for variety, following Dixit and Stiglitz (1977), let the composite $M$ be a subutility CES function defined over a range of varieties $i \in] 0 ; \hat{n}]$ and let $\sigma \equiv 1 /(1-\rho)$ indicate the constant elasticity of substitution in preferences between any pair of varieties

$M=\left[n(m(i))^{\rho}+n^{*}\left(m(j)^{*}\right)^{\rho}\right]^{\frac{1}{\rho}} \quad 0<\rho<1$

with the consumption of each local variety denoted by $m(i)$ and of each "imported" variety by $m(j)^{*}$. Centre varieties $n$ belong to the interval $\left.] 0 ; n\right]$; 
hinterland varieties $n^{*}$ belong to the interval $\left.] n ; \hat{n}\right]$. The representative household maximises (2) subject to (3) and to the budget constraint (4), where $Y$ is total regional income, $p_{M}$ the price of variety $i$ and $p_{H}$ the price of housing:

$Y=p_{H} H_{c}+R p_{H}^{*} H_{h}+G \cdot M \quad$ where $G \cdot M=\left[n p_{M} m(i)+n^{*} p_{M}^{*} m(j)^{*}\right]$

Equation (4) captures the price $p_{H}$ for housing in the home region $H_{c}$ and the price of housing in the other region including commuting costs, $p_{H}^{*} R$, with $R \geq 1$, for demand in the alternative region $H_{h}$. Index $G$ denotes the price index of the manufacturing composite $M$ as given in equation (3). ${ }^{1}$ See equation (5) for a specification of $G$, where parameter $T$ models passenger transport costs in consumption. These transport costs are assumed to be of the iceberg form introduced by von Thünen (1826) and Samuelson (1952), i.e. only a fraction 1/T of the transported good arrives in the other region. In other words, for each unit delivered $T$ units have to be shipped. In the present model, transport costs are incurred whenever residents decide to buy not in the local market but to purchase in the other region.

$G=\left[n\left(p_{M}\right)^{1-\sigma}+n^{*}\left(p_{M}^{*} T\right)^{1-\sigma}\right]^{1 /(1-\sigma)} \quad T \geq 1$

By use of the same technology, the producer price $p_{M}$ is identical for all firms within a region, i.e. with $p_{m}$ as the consumer price, $p_{m}(i)=p_{M}$ and $p_{m}^{*}(i)=p_{M}^{*}$ for all varieties $i .^{2}$ Utility maximisation yields the demand for consumption varieties and for housing. The demand for local and imported varieties is

$m(i)=\alpha Y \frac{p_{M}^{-\sigma}}{G^{1-\sigma}}$ and $m(j)^{*}=\alpha Y{\frac{\left(p_{M}^{*} T\right)^{-\sigma}}{G^{1-\sigma}}}^{-6}$

such that the demand for products manufactured in the centre, made up of its own demand and the demand of the hinterland, including goods to be shipped, adds up to

$$
m(i)+m(i)^{*}=\alpha\left[Y\left(p_{M}\right)^{-\sigma} G^{\sigma-1}+Y^{*}\left(p_{M}\right)^{-\sigma} T^{1-\sigma}\left(G^{*}\right)^{\sigma-1}\right]
$$

\footnotetext{
1 The price index is defined such that $G$ times $M$ is equal to expenditure: $\int_{0}^{\hat{n}} p_{m}(i) m(i) d i=G \cdot M$, where $G=\left[\int_{0}^{\hat{n}} p_{m}(i)^{1-\sigma} d i\right]^{1 /(1-\sigma)}$ and $M=\left[\int_{0}^{\hat{n}} m(i)^{\rho} d i\right]^{1 / \rho}$.

2 By assuming the same price for all varieties, for the case of costless transportation, $G$ (as defined in footnote 1), becomes $G=p_{M} \cdot \hat{n}^{1 /(1-\sigma)}$.
} 
Equations (2) to (7) work analogously for the hinterland. The housing demand by labour force per region $H$ is composed of demand from residents living on site (non-commuters) and from residents commuting from outside, i.e. $H=H_{c}+H_{h}$. While non-commuters demand housing in the region they work in, where demand is $H_{c}$ for the centre population and $H_{h}^{*}$ for the hinterland, residents who commute cross-regionally face higher housing prices due to commuting costs $R$ and thus demand $H_{h}$ and $H_{c}^{*}$. Hence, housing demand for each workforce can be written as (where the subscript refers to the place of residence, i.e. $c$ for centre and $h$ for hinterland, and the superscript for the place of work, i.e. an asterisk refers to the hinterland):

$$
\begin{array}{ll}
H=H_{c}+H_{h} & \text { for the centre } \\
H^{*}=H_{c}^{*}+H_{h}^{*} & \text { for the hinterland }
\end{array}
$$

where the demand for commuters and non-commuters are as follows (with $\beta$ defined as in equation (2)):

$$
\begin{array}{ll}
H_{c}=(1-\alpha) \beta \frac{Y}{p_{H}}, H_{h}^{*}=(1-\alpha) \beta \frac{Y^{*}}{p_{H}^{*}} & \text { for non-commuters } \\
H_{c}^{*}=(1-\alpha)(1-\beta) \frac{Y^{*}}{p_{H} R}, H_{h}=(1-\alpha)(1-\beta) \frac{Y}{p_{H}^{*} R} & \text { for commuters }
\end{array}
$$

Region-specific housing - in contrast to the labour force concept of demand functions in (8) - can be calculated from equations (9) and is composed of home demand and demand from residents who commute to the other region:

$$
\begin{array}{ll}
\bar{H}_{c}=H_{c}+H_{c}^{*} & \text { for the centre } \\
\bar{H}_{h}=H_{h}^{*}+H_{h} & \text { for the hinterland }
\end{array}
$$

\subsection{Housing}

As workers can migrate to the other region, but housing production is fixed in quantitative terms (not in terms of prices), oversupply in one region and undersupply in the other will occur. The arising changes in housing prices induce a fraction of the population in the more densely populated region to look for housing in the other region. 
The supply of housing goods is fixed at $\bar{H}_{c}=(1-\alpha) / 2$ in the centre and at $\bar{H}_{h}=P(1-\alpha) / 2$. The exogenous policy parameter $P$ is initially equal to 1 and will be used to restrict the supply of housing in the surroundings. The housing market is cleared by the Armington assumption of product heterogeneity ${ }^{3}$, which determines the degree to which the trade balance in housing varies. Thus, the housing demand of commuters $H_{h}$ and $H_{c}^{*}$ or, expressed differently, the "exported" quantities of the housing good, are determined by

$H_{c}^{*}=r_{c} \bar{H}_{c}\left(\frac{p_{H}^{*}}{p_{H} R}\right)^{\varepsilon}$ and $H_{h}=S r_{h} \bar{H}_{h}\left(\frac{p_{H}}{p_{H}^{*} R}\right)^{\varepsilon}$

where $S$ denotes the exogenous urban sprawl parameter which is initially set equal to one and will be used to increase the share of housing exports from the hinterland. A change in relative housing prices shifts the trade balance in housing by a certain degree which is given by $\varepsilon$, the Armington elasticity of substitution between home production of housing and imports. This shift corresponds to a shift in the settlement structure which is characterised by the allocation of residences and workplaces. The variables $r_{c}$ and $r_{h}$ denote the reference level of housing exports (at reference prices and corresponding income, both denoted by a zero for reference period), based on equations (10):

$r_{c}=\frac{H_{c}^{*}\left(p_{H, 0}, Y_{0}^{*}, R_{0}\right)}{\bar{H}_{c}}$ and $r_{h}=\frac{H_{h}\left(p_{H, 0}^{*}, Y_{0}, R_{0}\right)}{\bar{H}_{h}}$

\subsection{Environment}

In order to specify the level of environmental quality, we assume that emissions are solely caused by passenger transport and that differences between the two regions in terms of pollution caused are only due to traveling to work. It is both workers commuting cross-regionally (who we will refer to as "commuters" in the following) and workers whose region of residence coincides with the region they work in ("non-commuters") who contribute to pollution. By differentiating two regions of residence and two types of workers by mobility behaviour, we distinguish four groups of workers: Non-commuters in the centre (group 1), noncommuters in the hinterland (group 2), commuters originating in the centre

${ }^{3}$ Under the Armington assumption domestic housing goods are treated as qualitatively different from goods imported from the other region. 
(commuters to the hinterland) (group 3), and commuters originating in the hinterland (commuters to the centre) (group 4). To model these groups, we first need their share in the labour force per region, with $s$ representing the commuter share in the centre, and $(1-s)$ representing the centre's non-commuters. The shares are defined analogously for the hinterland, and thus

$s=\frac{H_{h}}{H},(1-s)=\frac{H_{c}}{H}, s^{*}=\frac{H_{c}^{*}}{H^{*}}$ and $\left(1-s^{*}\right)=\frac{H_{h}^{*}}{H^{*}}$,

with $H=H_{c}+H_{h}$ and $H^{*}=H_{c}^{*}+H_{h}^{*}$. To calculate the levels of environmental quality per region, we assume that commuters to the centre (group 4) contribute to the centre level of environmental quality $Q$ and commuters to the hinterland (group 3) contribute to the hinterland level $Q^{*}$. Moreover, each type of worker causes pollution by a group-specific environmental impact factor, which we denote by $\mu$. Having fixed this, the damage functions $D(s)$ and $D\left(s^{*}\right)$ from equation (1) can be specified as

$D(s)=-\left(\mu_{c}(1-s)+\mu_{h} s\right)$ and $D\left(s^{*}\right)=-\left(\mu_{h}^{*}\left(1-s^{*}\right)+\mu_{c}^{*} s^{*}\right)$

\subsection{Production}

We assume a manufacturing sector producing a heterogeneous consumption good, following Dixit and Stiglitz (1977). Production of all varieties requires labour and capital, and all firms use the same technology. The labour $l_{M}$ required to produce quantity $q_{M}$ of any variety $i$ involves fixed labour input $F$ and marginal labour input $a_{M}$ :

$l_{M}=F+a_{M} q_{M}$

Hence, there are increasing returns to scale in the production of each variety. A firm's demand for capital $k_{M}$ is determined by a constant capital-to-labour ratio $c_{M}=k_{M} / l_{M}$ (see Eppink and Withagen, 2006), which is identical for all firms. Firms earn economic rents by applying mark-up pricing, yet costless entry and exit drive profits to zero. Let $w_{M}$ be the wage rate, $p_{M}$ the f.o.b. price and $p_{K}$ the price of capital. Then, given demand for variety $i$ produced in the centre region (7), each firm producing a specific variety behaves so as to maximize profit $\pi=p_{M} q_{M}-\left(w_{M}+p_{K} c_{M}\right)\left(F+a_{M} q_{M}\right)$. The FOC, together with a constant price elasticity of demand, $\sigma=1 /(1-\rho)$, give the profit-maximising price $p_{M}$ for each 
variety as a fixed mark-up over marginal cost. Including the normalisation ${ }^{4}$ $a_{M} \equiv \rho$, this yields

$p_{M}=\frac{a_{M}\left(w_{M}+p_{K} c_{M}\right)}{\rho}=w_{M}+p_{K} c_{M}=y_{M}$

so that the profit-maximizing price equals per capita income in manufacturing from labour and capital.

${ }^{4}$ For standard normalizations used throughout the paper see e.g. Fujita et al. (1999). 



\section{Existence and stability of equilibria}

\subsection{Instantaneous equilibrium}

We determine the short-run equilibrium by deriving the equilibrium conditions for the endogenous variables $y_{M}, Y, G$ and $p_{H}$ in each region. The according outcome, i.e. an equilibrium for a given distribution $\lambda$ of manufacturing workers over the two regions, is characterised by optimising behaviour of consumers and firms and by market clearing. Due to the additively-separable form of the utility function (2), the demand functions do not depend on environmental quality $Q$. In the long-run, by contrast, environmental quality does affect the location decision of households.

Recalling that total labour supply $\bar{L}_{M}=\alpha$ and using the normalisations $a_{M} \equiv \rho=(\sigma-1) / \sigma$ and $F \equiv \alpha / \sigma$, at an instantaneous equilibrium a firm's labour demand equals its output, i.e. $l_{M}=q_{M}=\alpha$, while the demand for capital is $k_{M}=c_{M} \alpha$. The labour market and the capital market thus clear. The equilibrium number of firms, which equals the number of varieties produced, is then given by $n=L_{M} / \alpha=K_{M} /\left(c_{M} \alpha\right)$. It follows that the number of active firms $n$ is equal to the share of manufacturing labour $\lambda=L_{M} / \bar{L}_{M}, 0<\lambda<1$, in the respective region, so that $n=\lambda$ and $n^{*}=1-\lambda$.

Moreover, firms attain the equilibrium output if $q_{M}$ equals total demand for any variety as given in (7), thereby clearing the manufacturing market. This, together with the pricing rule (15) gives us the first pair of equilibrium conditions, i.e. the income of a manufacturing worker at which firms break even:

$y_{M}=\left[Y G^{\sigma-1}+Y^{*} T^{1-\sigma}\left(G^{*}\right)^{\sigma-1}\right]^{\frac{1}{\sigma}}$
$y_{M}^{*}=\left[Y^{*}\left(G^{*}\right)^{\sigma-1}+Y T^{1-\sigma} G^{\sigma-1}\right]^{\frac{1}{\sigma}}$

With $n=\lambda=L_{M} / \alpha, p_{M}=y_{M}$ and $w_{H}=p_{H}$ total income $Y$ per region is denoted by

$$
\begin{aligned}
& Y=\alpha \lambda y_{M}+p_{H} \frac{(1-\alpha)}{2} \\
& Y^{*}=\alpha(1-\lambda) y_{M}^{*}+p_{H}^{*} \frac{(1-\alpha)}{2}
\end{aligned}
$$


and the region specific price indices (as given in equation (5)) can be written as

$$
\begin{aligned}
& G=\left[\lambda\left(y_{M}\right)^{1-\sigma}+(1-\lambda)\left(y_{M}^{*} T\right)^{1-\sigma}\right]^{\frac{1}{1-\sigma}} \\
& G^{*}=\left[\lambda\left(y_{M} T\right)^{1-\sigma}+(1-\lambda)\left(y_{M}^{*}\right)^{1-\sigma}\right]^{\frac{1}{1-\sigma}}
\end{aligned}
$$

The housing market clears if regional supplies, $\bar{H}_{c}$ and $\bar{H}_{h}$, equal regional demands, as given in equations (9'). Hence, housing prices are

$$
\begin{aligned}
& p_{H}=2\left[\beta Y+(1-\beta) \frac{Y^{*}}{R}\right] \\
& p_{H}^{*}=2\left[\beta Y^{*}+(1-\beta) \frac{Y}{R}\right]
\end{aligned}
$$

\subsection{The price index effect and the home market effect}

The price indices and wage equations imply important relationships with respect to the spatial equilibrium. In particular, the regional equilibrium structure of real wage differences depends on the balance of three effects, namely (i) the price index effect (or cost of living effect) (ii) the home market effect (or market size effect) and (iii) the competition effect. The first and the second effect are agglomeration forces, while the third acts as a dispersion force.

In order to investigate agglomeration forces (i) and (ii), the price indices (see equations (18)) and real income equations (see equations (16)) can be rewritten as

$$
\begin{aligned}
& G^{1-\sigma}=\frac{1}{\alpha}\left[L_{M}\left(w_{M}+p_{K} c_{M}\right)^{1-\sigma}+L_{M}^{*}\left[\left(w_{M}^{*}+p_{K}^{*} c_{M}\right) T\right]^{1-\sigma}\right] \\
& \left(G^{*}\right)^{1-\sigma}=\frac{1}{\alpha}\left[L_{M}\left[\left(w_{M}+p_{K} c_{M}\right) T\right]^{1-\sigma}+L_{M}^{*}\left(w_{M}^{*}+p_{K}^{*} c_{M}\right)^{1-\sigma}\right] \\
& \left(w_{M}+p_{K} \cdot c_{M}\right)^{\sigma}=Y \cdot G^{\sigma-1}+Y^{*} \cdot T^{1-\sigma}\left(G^{*}\right)^{\sigma-1} \\
& \left(w_{M}^{*}+p_{K}^{*} \cdot c_{M}\right)^{\sigma}=Y^{*}\left(G^{*}\right)^{\sigma-1}+Y \cdot T^{1-\sigma} G^{\sigma-1}
\end{aligned}
$$

Since these pairs of equations are symmetric, they have a symmetric solution, i.e. if $L_{M}=L_{M}^{*}$ and $Y=Y^{*}$, then the equilibrium values are equally symmetric: $G=G^{*}$ and $w_{M}+p_{K} c_{M}=w_{M}^{*}+p_{K}^{*} c_{M}$, more specifically $w_{M}=w_{M}^{*}$ and $p_{K}=p_{K}^{*}$. The relationship between these equilibrium values can be expressed by 
$1+T^{1-\sigma}=\frac{\alpha}{L_{M}} \cdot\left(\frac{G}{w_{M}+p_{K} c_{M}}\right)^{\sigma}=\frac{w_{M}+p_{K} c_{M}}{Y} \cdot\left(\frac{G}{w_{M}+p_{K} c_{M}}\right)^{\sigma}$

By totally differentiating the price indices around the symmetric equilibrium and letting $\quad d G=-d G^{*}, \quad d L_{M}=-d L_{M}^{*}, \quad d\left(w_{M}+p_{K} c_{M}\right)=d\left(w_{M}^{*}+p_{K}^{*} c_{M}\right) \quad$ and $d Y=-d Y^{*}$, we get

$$
(1-\sigma) \frac{d G}{G}=\frac{L_{M}}{\alpha}\left(\frac{G}{w_{M}+p_{K} c_{M}}\right)^{\sigma-1} \cdot\left(1-T^{1-\sigma}\right) \cdot\left[\frac{d L_{M}}{L_{M}}+(1-\sigma) \frac{d\left(w_{M}+p_{K} c_{M}\right)}{w_{M}+p_{K} c_{M}}\right]
$$

Applying the same for the wage equations yields

$$
\sigma \frac{d\left(w_{M}+p_{K} c_{M}\right)}{w_{M}+p_{K} c_{M}}=\frac{Y}{w_{M}+p_{K} c_{M}} \cdot\left(\frac{G}{w_{M}+p_{K} c_{M}}\right)^{\sigma-1} \cdot\left(1-T^{1-\sigma}\right) \cdot\left[\frac{d Y}{Y}+(\sigma-1) \frac{d G}{G}\right]
$$

In both equations (23) and (24), the term $\left(1-T^{1-\sigma}\right)$ captures the effects of an increase in a variable in one region and the corresponding decrease in the other.

To explore the price index effect, let us consider equation (23), thereby assuming $d w=0$, i.e. a perfectly elastic supply of manufacturing labour, for a moment. We find that an increase in manufacturing labour $d L_{M} / L_{M}$ lowers the price index:

$$
\frac{d G / G}{d L_{M} / L_{M}}<0
$$

In order to investigate the home market effect, let us define a new variable $Z$, which is an index of transport costs.

$$
Z \equiv \frac{1-T^{1-\sigma}}{1+T^{1-\sigma}}
$$$$
0 \leq Z \leq 1
$$

When there are no transport costs, i.e. $T=1$ (free trade), $Z=0$. When, on the other hand, transport costs are prohibitively high, i.e. $T \rightarrow \infty$ (trade is impossible), $Z=1$.

Eliminating $d G / G$ from equations (23) and (24) yields

$$
\left[\frac{\sigma}{Z}+Z(1-\sigma)\right] \frac{d\left(w_{M}+p_{K} c_{M}\right)}{w_{M}+p_{K} c_{M}}+Z \frac{d L_{M}}{L_{M}}=\frac{d Y}{Y}
$$


This equation implicates the home market effect, i.e. assuming $d w=0$, an increase in demand for the manufacturing good $d Y / Y$ causes a more than proportional rise in the employment and production of manufactures $d L_{M} / L_{M}$ :

$\frac{d L_{M} / L_{M}}{d Y / Y}=\frac{1}{Z}>1$

What follows is that the location with the larger home market also exports manufactured goods. Otherwise, with an upward sloping labour supply curve, the positive effect $1 / Z$ is smaller for the sake of higher nominal wages and less exports. Then, the important point is that locations with a higher demand for manufactures offer higher real wages both because (i) the nominal wage is high due to the market size effect and (ii) the price index is low due to the cost of living effect.

Summing up, the home market effect and the price index effect are key elements of cumulative causation that lead to agglomeration. Generally speaking, because of increasing returns, it is advantageous to concentrate production at a few locations. The best locations are those with good access to markets and suppliers and where mobile factors of production have been attracted to. More specifically, backward linkages - the use by one firm of produced inputs from another firm, create an incentive for producers to concentrate where the market is large. This is equally true for forward linkages - the provision by one firm of produced inputs to another firm. As for workers, backward and forward linkages create an incentive for them to be close to the production of consumer goods: The larger is the manufacturing sector, the lower is the price index for manufactured goods, because a larger variety of goods is produced locally (price index effect). Going further, the higher is the demand for manufactures, i.e. the larger the manufacturing sector, the higher is the real wage paid to workers (home market effect).

\subsection{Long-run equilibrium}

In this section we analyse what happens to the settlement structure in the long run, in particular we study how adjustment processes result in a specific population split expressed by the value of $\lambda$. The driving force in the migration process is the residents' utility differential between the core and the hinterland region. A long-run equilibrium, i.e. a short-run equilibrium in which the allocation of mobile workers $\lambda$ is also in equilibrium, occurs when no resident may get a higher utility level by 
changing location. We call the according distribution $\lambda \in[0,1]$ a spatial equilibrium, which arises therefore at

$\begin{array}{lll}0<\lambda<1 & \text { when } & \Delta u_{M} \equiv u_{M}(\lambda)-u_{M}^{*}(\lambda)=0 \text { or at } \\ \lambda=1 & \text { when } & \Delta u_{M}(1) \geq 0 \text { or at } \\ \lambda=0 & \text { when } & \Delta u_{M}(0) \leq 0\end{array}$

Recall from section 2, that we distinguish four groups of workers: commuters and non-commuters who either live in the centre or in the surroundings. According to (12) and acknowledging that commuter shares depend on the equilibrium centre labour force $\lambda$, these groups, $g_{1}, g_{2}, g_{3}$ and $g_{4}$, can be written as

$g_{1}=(1-r) \lambda, g_{2}=\left(1-r^{*}\right) \lambda, g_{3}=r^{*}(1-\lambda)$ and $g_{4}=r(1-\lambda)$.

We assume a myopic adjustment process, i.e. workers are attracted by the region that has a higher utility than the average utility (over both regions). A gradual migration process stems from the fact that residents have different moving costs. Migration is thus governed by the ad hoc adjustment dynamics (Fujita et al., 1999) ${ }^{5}$

$$
\dot{\lambda}=\Delta u_{M}(\lambda) \lambda(1-\lambda) \Leftrightarrow \dot{\lambda}=\left[\left(\omega-\omega^{*}\right)+\delta\left(Q-Q^{*}\right)\right] \lambda(1-\lambda)
$$

Since in the long run no resident has an incentive to relocate, a spatial equilibrium implies $\dot{\lambda}=0$. If the utility differential $\Delta u_{M}$ is positive, there is an incentive for some workers to move from the hinterland to the centre, and vice versa for a negative differential.

Figure 1: Migration between the centre and the hinterland region

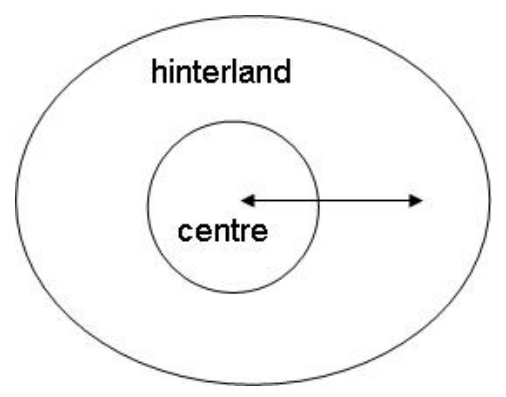

5 These dynamics are equivalent to the replicator dynamics used in evolutionary game theory. Hereby, subpopulations that are associated with better-than-average strategies grow, while those associated with worse-than-average strategies decline In particular, $\dot{\lambda} \equiv d \lambda / d t=\left(u_{M}-\bar{u}_{M}\right) \lambda$ with $\bar{u}_{M}=\lambda u_{M}+(1-\lambda) u_{M}^{*}$ with $t$ being time (e.g. Weibull, 1995). 
The migration dynamics is governed by households who choose the location to settle that offers the higher level of welfare. In this way, the urban residential dynamics is an outcome of all the households' simultaneous individual choices. For the present model, household residential choice depends on differences in real income $\omega$ and in environmental quality $Q$. Residents face two trade-offs which differ in terms of substitutability: First, workers choose the consumption good and housing at a cost. Second, households face a trade-off between goods they pay for in monetary terms and environmental quality.

Thus, the representative household splits income $Y$ between $M, H_{c}$ and $H_{h}$. Each variety $m(i)$ and $m(i)^{*}$ is chosen such that the costs of attaining $M$ as determined in the first step are minimized. Expressing the consumers' maximised utility as a function of income and prices yields the indirect utility function

$u_{M}=\omega \Omega+\delta Q=y_{M} G^{-\alpha}\left(p_{H}^{\beta}\left(p_{H} R\right)^{1-\beta}\right)^{-(1-\alpha)} \Omega+\delta e^{D(s)}$

where $y_{M}$ is per capita income in manufacturing and $\omega$ its real wage, i.e. $\omega=y_{M} /\left(G^{\alpha}\left(p_{H}^{\beta}\left(p_{H} R\right)^{1-\beta}\right)^{(1-\alpha)}\right) ; \Omega=\alpha^{\alpha}(1-\alpha)^{1-\alpha}\left(\beta^{\beta}(1-\beta)^{1-\beta}\right)^{1-\alpha} \quad$ is a constant. The per capita utility, as we will later see, determines the manufacturing workers' location decision, since residents choose the region to settle where their utility is maximised. By this means, the welfare of a worker is given by equation (33) evaluated at equilibrium prices.

\subsection{Existence and stability conditions}

We shall investigate the existence of equilibria by means of equations (32) and (33). The most obvious spatial equilibrium arises with equality in real income $\omega$ and environmental quality $Q$ across regions. For this equality it can be easily seen that the utility differential is zero. Alternatively, the difference in real income levels may be compensated by the difference in environmental quality (with opposite sign). In particular, the spatial equilibrium is in this case characterised by either $\omega>\omega^{*}$ and $Q<Q^{*}$, or $\omega<\omega^{*}$ and $Q>Q^{*}$. Thus, for a lower $\omega$ (relative to the other region) residents are compensated by a higher $Q$ and vice versa for a relatively low level of $Q$. With otherwise identical regions such an equilibrium is the consequence of environmental differentiation between the regions.

For the model specified in Section 2, a solution exists for the following combination of parameter values, where the crucial parameters model the housing 
market: the commuting cost factor $R$ and the preference for commuting $\beta$. Thus, for zero commuting costs $(R=1)$, a solution exists only if there is no indifference in the residential choice $(\beta \neq 0.5)$, or if there is no full aversion to commuting $(\beta \neq 1)$. The two special cases described below will further illustrate these conditions.

A spatial equilibrium is asymptotically stable if, for any marginal deviation of the population distribution from the equilibrium, the model dynamics brings the distribution of mobile labour back to the original one. ${ }^{6}$ The distribution to be analysed for the model on hand, which is the dispersed configuration with $0<\lambda<1$, is stable if and only if the slope of $\Delta u_{M}$ is non-positive in a neighbourhood of this point.

In order to derive the stability conditions, let us assume identical regions with respect to the production of manufacturing and housing and also with regard to environmental impacts. Now consider a situation where residents are equally spread between the regions such that $\lambda=1 / 2$. With identical regions this must be an equilibrium since $\omega=\omega^{*}$ and $Q=Q^{*}$ and thus $u_{M}=u_{M}^{*}$. By totally differentiating (33) around the symmetric steady state with respect to $\lambda$ we derive $d u_{M} / d \lambda$, the equilibrium respond, which is the change in per capita utility caused by a movement of residents,

$\frac{d u_{M}}{d \lambda}=\frac{d \omega}{d \lambda}+\delta \frac{d Q}{d \lambda}$

For the full notation of (34) and its derivation we refer to the Appendix (A.1). If $d u_{M} / d \lambda$ is negative for the exogenous parameter values of $\sigma, \alpha, \delta, \mu, T$ and $R$, the symmetric case $\lambda=1 / 2$ is a stable equilibrium and vice versa for a positive value. Moreover, the symmetric solution is characterized by identical environmental damage parameters across regions.

We identify two special cases, where solutions do not exist. First, we find the case of complete preference for housing close to the workplace such that there is no commuting ( $\beta=1$ ) and thus commuting costs $R$ become irrelevant. Second, there is the case of complete indifference in the housing decision together with costless commuting ( $R=1$ and $\beta=0.5$ ). In the first case where $\beta=1$, the equilibrium outcome for $\lambda$ is independent from $Q$, and thus $d Q=0$. Environmental effects are

\footnotetext{
${ }^{6}$ In order to study stability of the equilibrium, if some workers migrate to the other region, local markets are assumed to adjust instantaneously. In particular, the number of firms in each region must be such that equation (33) remains valid for the new settlement structure of residents. Then, wages are adjusted such that firms earn zero profits.
} 
absent due to the specification of environmental quality (see equations (1) and (14)), while changes in the remaining variables ((A2) to (A5) in the Appendix) remain non-zero. However, there is no differentiation between commuters and noncommuters. The location of residence always coincides with the place of work, implying that the model dynamics is not of further interest for us.

By contrast, for the combination of indifference in housing and free commuting, $R=1$ and $\beta=0.5$, environmental effects are absent because there is no change in housing prices with different equilibrium outcomes for $\lambda$. I.e. $d Q=0$ because $d p_{H}=0$. Workers are completely indifferent between home production of housing and imports ( $\beta=0.5)$ and, in addition, do not pay for commuting $(R=1)$. 


\section{Policies to reduce transport emissions}

Current transport-related environmental challenges as well as health and noise effects clearly call for a reorganisation of transport systems. The aim is to achieve environmentally friendly mobility and access options, thereby directing long-term impacts on transport structures.

Central to the idea of policy selection is the spatial restructuring of the concerned areas in order to steer motorised transport patterns. An increase in operating costs of car transport, for example, will change transport behaviour, but it is expected to have major effects on individual location decisions only in the long run. On the contrary, a spatial planning measure ideally steers workplaces and housing decisions in such that a way that short distances can be travelled and public transport is feasible also in peripheral regions. Further more, in urban cores the support of dense housing structures is essential together with a high quality of living. The current design of urban centres, however, and the application of misleading transport policies, often support urban sprawl and cause a degradation of environmental quality. It is therefore important to increase the attractiveness of city centres, but also to regulate land use in the surrounding region in order to create mixed-used areas with high density. As a consequence, public transport infrastructure would be supported resulting in a lower car dependency in the overall region (OECD, 2005).

The following survey comprises a selection of policy measures we consider suitable for directing impacts on transport structures to address motorised transport related pollution. In this respect, we include regulatory instrument and spatial planning measures as well as pricing policies to internalise external costs of transport (environment, health, noise). The list comprises both long-term instruments and instruments available for short-term effects, for which we collected suitable instruments from a recent OECD study (OECD, 2005) and two national case studies for Austria (Friedl et al., 2000; Schleicher et al., 2005).

\subsection{Spatial planning measures}

\subsubsection{Adaptation of provincial land use regulation}

The adaptation of zoning regulations should focus on newly dedicated building land, especially land used for residential areas. It is suggested to intermit new dedications until the already existing building land is exhausted. Such a regulation 
could by this means prohibit the zoning of further areas of free land before the currently zoned land is used for construction. (Prettenthaler et al., 2002).

In Austria, land use regulation is set at the provincial level of government. Actually one third of the building land in Austria is not used; for the NUTS III region Graz (province Styria) it is in fact 60\% (Weber and Griesser, 2006). This obviously paradox status of building land is a consequence of political pressure and competing municipalities. Possible approaches towards a limitation of further dedications include the cooperation between municipalities and the creation of a suitable framework to realise effective spatial planning policies. Other deficiencies in Austrian spatial planning comprise an excess of complimentary dedications (Gefälligkeitswidmungen) and privileges as well as a lack of instructions for implementation (Realisierungsanweisungen).

In this context, Finland, which is 2.5 times the size of Austria, serves as an inspiring example: 400 municipalities have been reduced to 25 in order to save money and to clear up any fiscal reasons for ill-advised land use. By contrast, Austria is highly small-sized structured, with the province of Styria on its own comprising 542 municipalities.

\subsubsection{Charges for the provision of public infrastructure (aimed at idle building land in central locations)}

In Austria, a lot of centrally located building land is held back idle by their owners for investment reasons. This behaviour hinders dense living and good access to public infrastructure. It is therefore suggested for lots of land within zones that are devoted to construction activities, yet currently not used, to be included in the tax scheme on land value. The measures include e.g. charges for the development and provision of the local public infrastructure aimed at central locations, i.e. if the site is within a certain distance of a public transport connection. Hereby, these charges foster the creation of mixed-use areas with high density.

Ideally, the spatial structure of production and consumption should be characterised by a spatial mixture of uses and polycentrism, consisting of various subcentres of different size with different functional mixes. This is for two reasons mainly: First, mixed-use areas allow for a minimisation of travel distances and promote public transport infrastructure, thereby enabling an improved possibility to switch to more environmentally favourable transport modes. A second point is that the functional mix of these centres (and that of the overall agglomeration) should not only consist of mixed use for living and working but of a mix of all major requirements of everyday life including leisure, shopping and health care facilities. 
This would thus also decrease the requirement for interurban transport (OECD, 2005).

The Austrian province of Salzburg at least partially solved the problem of idle building land by introducing limited dedications for construction activities with the possibility of a re-dedication. In particular, building land is re-dedicated if the land owner does not implement the previously declared local plan and use of land within 10 years. However, this limitation does not touch existing dedications.

\subsubsection{Restructuring of funding schemes for housing construction and development}

While zoning regulation is the more direct instrument to address urban sprawl and induced traffic, the reorientation of funding schemes for housing construction can contribute to reduce transport emissions, too. In particular, the restructuring of residential funding schemes is able to steer long-term transport demand via its influence on spatial structures.

Funding schemes for housing currently exist largely without any reference to public transport accessibility. The essential point is to raise subsidy rates for buildings close to areas well-served by public transport. It is suggested that funding of residential property be reduced if the construction site is not within a certain distance of a public transport connection. In urban areas, additionally, subsidies for new constructed homes should be redirected to the remodelling of old houses. New homes - predominantly single-family houses, primarily constructed on the outskirts - induce transport and additional environmental effects unless the provided public transport infrastructure offers proper accessibility. Thus, beside the consumed space, new homes require additional transport infrastructure (Prettenthaler et al., 2002). In Austria, subsidies for new constructions are trice the rate directed at the restoration of old houses (Cerveny and Tretter, 2003).

As a result, the mentioned measures promote dense living in two different aspects: On the one hand, they reduce urban sprawl and foster dense living in central regions. On the other hand, they promote dense living in peripheral areas and therefore support public transport. An accessory effect in urban areas is reduced energy consumption, since new houses may be better isolated due to stronger legal requirements. 


\subsection{Other instruments}

\subsubsection{Fixed tax allowances for commuters}

The Austrian Law determines that expenditures for trips to and from the working place are tax-deductible. For trips which are longer than $20 \mathrm{~km}$ and for which the use of public transport is possible and reasonable there is the deductibility of a lump-sum per year. It is also called "small fixed tax allowance for commuters". For trips smaller than $20 \mathrm{~km}$ and longer than $2 \mathrm{~km}$ where the use of public transport is neither possible nor reasonable the "big fixed tax allowance for commuters" is deductible.

The current supporting scheme for commuters in Austria clearly tends to work in favour of longer commuting distances and also fosters private car use. A possible reform of the current refunding scheme for commuters would suggest to equally treat all modes of transport and, secondly, to couple the deductibility for commuters with the ownership of a season ticket. This would give an additional incentive to favour public transport and could therefore avoid the negative effects accompanying the use of car (emissions, congestion, accidents).

The question remains how these reform options could be achieved and which additional advantages can emerge. The reduction of different schemes would not only simplify administration but would also imply that the same lump-sum deductible would hold for any mode of transport, and that the incentive to buy and use a private car would be abolished. However, if an individual incurred actual costs from commuting that are higher than prescribed by this scheme, the person would still have to be allowed to claim a deductible equal to the actual cost for legal reasons.

\subsubsection{Parking management for central regions: Strict parking restrictions and/or provision of park \& ride facilities}

The aim of parking management measures is to steer transport demand in cities. For example increasing parking fees or introducing strict parking restrictions could reduce the number of total trips. Another measure would be to construct attractive park\&ride facilities inducing people to switch to public transport. Thus, parking options may be managed in various ways, on their own or as combined measures, such as (i) the reduction in the number of parking lots in central regions (regulatory instrument), (ii) the increase of parking fees (fiscal), and (iii) the provision of park\&ride facilities on the outskirts (investment), thereby offering connections at frequent intervals and at moderate prices. Parking fees, however, represent a 
second-best solution only, if compared to other fiscal instruments such as road pricing. This is due to the fact that it is primarily the number of trips which are reduced and not the total of vehicle miles travelled (reflected by the trip length) (Verhoef, 1996).

\subsection{Fiscal instruments / pricing policies}

\subsubsection{General road pricing}

Road pricing schemes bind motorists to pay directly for using a specific section of the road network, thus steering transport demand via prices. They aim to cover infrastructure maintenance costs and internalise environmental and health costs of passenger transport. Moreover, if pricing measures are accompanied by the promotion of public transport, a more desirable spatial structure of consumption can be supported via the spatial allocation of investments.

Increased operating costs of passenger road transport will make motorised individual transport more expensive and thus less attractive. As a consequence, broadly speaking, there are fewer total vehicle miles travelled, which directly eliminates emissions of harmful pollutants. What happens in detail is that, firstly, high road transport costs make alternative modes of transport more attractive; yet modal shift is only possible where alternatives do exist. Secondly, urban areas may gain in attractiveness relative to rural regions because they are characterised by a low car-dependency and short distances. As a consequence, people would have an incentive to move closer to their workplace, which weakens the trend of urban sprawl (OECD, 2005).

As for freight transport, road pricing systems are expected to have an impact on transport intensive industries, especially on the primary industry (Puwein, 2000). As a result, firms will change location in order to be close to upstream/downstream producers.

\subsubsection{Cordon pricing}

Cordon pricing is a particular form of congestion pricing. In general, congestion pricing provides a disincentive to drive on highly used roadways by imposing fees. These fees are intended to reduce congestion and improve air quality by encouraging people to change their travel patterns, i.e. shifting to off-peak periods, to less congested roads or to public transport. In particular, cars that enter a highactivity area, such as a central business district, are charged. The concerned area is encircled with a cordon such that fees are collected via toll booths or parking 
permits from people driving into the respective region. Moreover, prices may vary by time of day in order to address peak congestion periods. Emissions of harmful pollutants will be mitigated because vehicle miles travelled will decrease. In particular, the imposed fees will result in people switching to higher occupancy vehicles or mass transport. In addition, idling, which is known to contribute significantly to carbon dioxide emissions and global warming, will decline. Other environmental benefits may result from lower oil and fuel consumption.

Cordon pricing systems are most effective in concentrated areas, thereby relieving inner-city congestion. However, there are also disadvantages to be mentioned. Cordon pricing may not reduce traffic on the region's freeway system leading into the city. Furthermore, such an instrument could result in an inequitable situation for downtown business if people decide to shop in the suburbs.

Regarding equity issues, cordon pricing may in general benefit high income groups, which tend to value time savings more than travel cost savings, while moderate income groups may benefit only if the revenue generated from the congestion pricing measure is used to construct or improve already existing mass transport systems. Thus, if congestion pricing policies successfully encourage people to switch to mass transport, the generated revenue may be used for transportation improvements (EPA, 1998).

\subsubsection{Tradable permit systems for $\mathrm{CO}_{2}$ emissions of transport}

The European Emission Trading Scheme (EU-ETS) was implemented as a $3^{\text {rd }}$ flexible mechanism of the Kyoto protocol in January 2005. Some 12,000 large industrial plants ( $46 \%$ of the EU's total $\mathrm{CO}_{2}$ emissions) currently participate in the first 3 years phase of this trading system. The scheme allows companies to buy and sell permits to release carbon dioxide into the atmosphere, so called allowances. Following so called national NAPs (National Allocation Plan), the number of allowances allocated to companies (caps) and the method to allocate them is set at EU member state level. Companies exceeding their individual $\mathrm{CO}_{2}$ emissions targets can purchase allowances from others who fall below them in order to reduce emissions, where it is cheapest, and to encourage switching to a low emission fuel mix and investments in new climate friendly technologies.

Cars and airplanes are major sources of the carbon dioxide emissions linked to climate change. Neither is currently covered by the scheme that gives industry incentives to cut $\mathrm{CO}_{2}$. The European Commission is currently reviewing the scheme and may recommend expanding it to other sectors, such as transport. While the Commission will soon put forward plans to include airlines, the inclusion of the transport sector seems unlikely before 2010, however. 


\section{The CGE model}

The theoretical model, characterized by equations (17), (18), (19) and (20) in Section 2, constitutes a 2-region general equilibrium model. We use this model for the analysis of core forces in urban sprawl. Being interested in the equilibria that this system tends to, we need to explore system behaviour under the specification of particular functional forms and parameters. We thus numerically solve this system, i.e. we apply spatial computable general equilibrium analysis.

As a baseline scenario, we assume that the two regions are perfectly identical except for environmental effects. In particular, the emission parameters differ between the center and the hinterland. As a consequence, the equilibrium value of $\lambda$ and the arising size of the four groups of workers are not symmetric across regions. Secondly, to illustrate urban sprawl in our model, we assume that commuting across regions is promoted and thus the population in the hinterland increases while the center population falls. Thirdly, we investigate the consequences of two policy instruments which are implemented in order to internalize the environmental consequences of urban sprawl. Thus, the environmental quality in these policy scenarios is, starting from the sprawl situation, improved towards the baseline level.

Thus, in the present section, we describe the empirical implementation of the theoretical model derived in Section 2 and analysed in Section 3. As a first step, we describe the empirical domain we have in mind when analysing different policy instruments. Next, we specify the calculation of the emission factors, taking account of differences across the two regions and the trip type (intraregional trips or cross-regional commuting). Building on these data sets and parameters, we briefly describe the estimation of the remaining parameters necessary to specify the CGE model. In doing so, we characterise the baseline scenario and then go on to describe how urban sprawl is modelled.

\subsection{The test region: Graz and its hinterland}

In order to test the model empirically, we apply a two-regional split up of economic data of the NUTS III region Graz (Austria), derived by using the provincial input-output structure of NUTS II region Styria. In particular, the addressed NUTS III region consists of the two political districts Graz city and Graz hinterland. 
Past decades have shown a strong movement of Graz city population towards its hinterland. Table 1 indicates an increasingly dispersed settlement structure with a rise in share of hinterland residents from $28.6 \%$ in 1971 to $36.7 \%$ in 2001 of total NUTS III region population.

Table 1: Development of population split up in NUTS III region Graz

\begin{tabular}{ccccc} 
& Graz city & share [\%] & Graz hinterland & share [\%] \\
\hline 1971 & 249,089 & 71.4 & 99,806 & 28.6 \\
1981 & 243,166 & 69.6 & 106,343 & 30.4 \\
1991 & 237,810 & 66.8 & 118,048 & 33.2 \\
2001 & 226,244 & 63.3 & 131,304 & 36.7 \\
\hline
\end{tabular}

Source: Statistik Austria, population census 2001

Taking account of trips to work only, the shares of commuters to the work force in the two regions currently are $26 \%$ for Graz centre and $22 \%$ for Graz hinterland. The net flow of commuters, which corresponds to $\dot{\lambda}$ in our model in chapter 3 , is equal to $-23,520$ (see Table 2).

Table 2: Transport flows for commuting in the NUTS III region Graz

\begin{tabular}{|c|c|c|c|}
\hline & & $\begin{array}{c}\text { number of } \\
\text { commuters }\end{array}$ & $\begin{array}{c}\text { share of } \\
\text { commuters }\end{array}$ \\
\hline \multicolumn{4}{|l|}{ non-commuters } \\
\hline Graz centre & & 86.748 & \\
\hline $\begin{array}{l}\text { Graz hinterland } \\
\text { commuters }\end{array}$ & & 14.612 & \\
\hline Graz centre to hinterland & & 7.168 & \\
\hline Graz hinterland to centre & & 30.688 & \\
\hline flow of commuters & & -23.520 & \\
\hline \multirow[t]{2}{*}{ labour force (by workplace) } & centre & 117.436 & $26,13 \%$ \\
\hline & hinterland & 21.780 & $32,91 \%$ \\
\hline
\end{tabular}

Source: Statistik Austria, population census 2001.

As illustrated by Figure 2, we observe an increase in the number of commuters in both directions. This trend towards urban sprawl is a result of changed lifestyles and rising per capita income, together with a high degree of motorisation and accessibility by road in the hinterland. The housing decision of residents is torn between different advantages prevailing in each region. While the centre offers for example wide-ranging job opportunities and shopping facilities, the hinterland is more attractive in terms of environmental quality. 
Figure 2: Development of commuters within the NUTS III region Graz

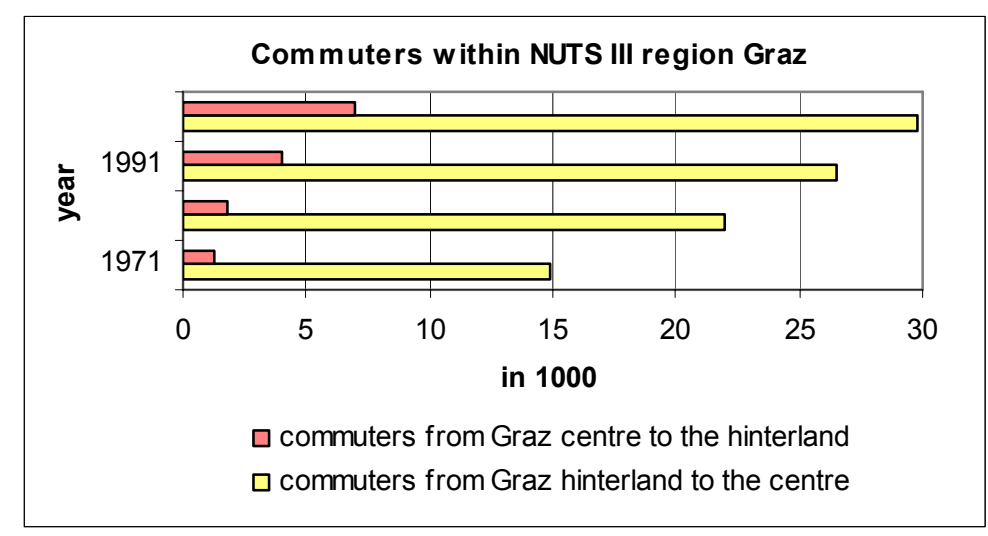

Source: Statistik Austria, population census 1971, 1981, 1991 and 2001

\subsection{Environmental impacts from passenger transport}

The study region is characterised by a very dynamic development with substantial detrimental effects in the transport sector. These include high amounts of local pollutants like particulate matter $\left(\mathrm{PM}_{10}\right)$. One the one hand, concentration levels are high due to large amounts of emissions. On the other hand, this development is due to high levels of ground $\mathrm{PM}_{10}$ that are raised by commuters when no reduction processes are at work. These high levels of $\mathrm{PM}_{10}$ concentration constitute a currently serious problem in Austria. This is particularly the case in inversion layer weather situations, which some cities - like Graz - are subject to due to their basinlike topography. We are thus interested in analysing transport related $\mathrm{PM}_{10}$ levels in cities.

Recall from Section 2 that by assumption emissions are solely caused by passenger transport and that differences between the two regions in terms of causing pollution are mainly driven by commuting to work. Since it is both commuters and noncommuters who contribute to pollution, we calculate emissions for a total of four groups of workers. They differ by region of residence (Graz centre or Graz hinterland) and whether they commute to work or not (see Table 3). In order to estimate emissions for each group, we have to calculate emission factors per group first. In doing so, we consider both $\mathrm{PM}_{10}$ emissions (Steininger et al., 2007) as well as the importance of raising $\mathrm{PM}_{10}$ and vehicle-related dust (Stefan Hausberger, personal communication; Steininger et al., 2007). 
Table 3: Modal split, $\mathbf{P M}_{10}$ emission factors per person-kilometer and commuter group, and emissions per trip and commuter group

\begin{tabular}{|c|c|c|c|c|c|c|}
\hline & \multicolumn{4}{|c|}{ modal split } & \multirow{2}{*}{$\begin{array}{c}\begin{array}{c}\text { PM } \\
\text { emission } \\
\text { factor }\end{array} \\
{[g / p-k m]}\end{array}$} & \multirow{2}{*}{$\begin{array}{c}\mathrm{PM}_{10} \\
\text { emissions } \\
{[\mathrm{g} / \text { trip }]}\end{array}$} \\
\hline & $\begin{array}{l}\text { walking / } \\
\text { bike }\end{array}$ & car & motorbike & $\begin{array}{c}\text { public } \\
\text { transport }\end{array}$ & & \\
\hline \multicolumn{7}{|l|}{ non-commuters } \\
\hline centre (group 1) & $27 \%$ & $47 \%$ & $2 \%$ & $24 \%$ & 0,040 & 0,04 \\
\hline hinterland (group 2) & $37 \%$ & $58 \%$ & $3 \%$ & $2 \%$ & 0,043 & 0,22 \\
\hline \multicolumn{7}{|l|}{ commuters } \\
\hline to hinterland (group 3) & $2 \%$ & $86 \%$ & $1 \%$ & $10 \%$ & 0,064 & 0,64 \\
\hline to centre (group 4) & $1 \%$ & $82 \%$ & $1 \%$ & $16 \%$ & 0,063 & 0,63 \\
\hline
\end{tabular}

Source: Käfer et al. (forthcoming); Hausberger (2007); Steininger et al. (2007); own calculation

Since our model does not distinguish different modes of transport explicitly, we have to calculate a weighted average for the emission factors. Thus, the specific emissions per person-km and mode (as summarized in the column " $\mathrm{PM}_{10}$ emission factor" of Table 3) reflect the respective modal split for the four groups (see the four columns "modal split" in Table 3). Furthermore, the region-specific occupancy rate for Graz and its hinterland for motorised individual transport are derived from the Austrian transport forecast (taking a value of 1.05) (Käfer et al., forthcoming), while we use an occupancy rate of 10 for public transport in the Graz region (Steininger et al., 2007).

Moreover, we have to consider the average distance driven. The average distance driven is lowest within the centre region, approximately five times longer for those within the hinterland region and approximately 10 times higher for those commuting from one region to the other (Käfer et al., forthcoming; Steininger et al., 2007). Thus, by taking account of trip distances, the resulting $\mathrm{PM}_{10}$ emissions per trip and consumer group are summarized in the last column of Table 3 . These values will be used in our model runs as follows: 0.22 for group 1, 0.44 for group 2, and 0.64 for groups 3 and 4 .

Note that since the modal split for those living and working in Graz is much less car dependent than of those commuting from Graz hinterland to Graz centre, and since the specific emissions of cars (per person-km) are much higher than for public transport, the resulting weighted emission coefficient is lower for the group of residents who do not commute. In the following, we assume the modal shares and the emission factors, accordingly, for each group to be constant. 


\subsection{The reference specification and the baseline scenario}

\subsubsection{The reference specification}

As a first step, we will briefly describe the (long-run) equilibrium in the case without policy interventions. This case will serve as a reference case to compare the policy simulations to. Let us first specify exogenous parameters and initial variables as introduced in the theoretical model in order to calibrate the reference equilibrium; the values are given in Table 4 and Table 5. For the description and normalizations of the remaining variables we refer to Appendix A.2.

In manufacturing labour and capital are employed in a Cobb-Douglas production technology. In order to differentiate between the place of work and residence of the manufacturing workers (interregional commuting), we let the housing good be traded, while the workforce in housing remains an immobile factor of production. Cross-regional commuters who work in the centre and live in the hinterland hence "import" the housing good from the peripheral region (and vice versa for imports from the centre). Since the housing production is fixed in quantitative terms in each region, the arising changes in housing prices induce a fraction of the population in the more densely populated region to look for housing in the other region; a fraction that is growing as long as the other region has cheaper housing prices net of commuting costs.

Table 4: The parameter values

\begin{tabular}{|c|c|c|}
\hline parameter & value & description \\
\hline $0 \leq \alpha \leq 1$ & 0.8 & expenditure share consumption good (own calculation for Graz area) \\
\hline $1-\alpha$ & 0.2 & expenditure share housing \\
\hline $0<\rho<1$ & 0.8 & intensity of preference for variety (Eppink and Witthagen, 2006) \\
\hline$\sigma=1 /(1-\rho)$ & 5 & $\begin{array}{l}\text { elasticity of substitution between varieties (Eppink and Witthagen, } \\
2006 \text { ) }\end{array}$ \\
\hline$\delta>0$ & 5000 & scaling parameter for environmental quality (in utility) \\
\hline$\mu_{c} \geq 0$ & 0.22 & $\begin{array}{l}\text { environmental damage parameter for group } 1 \text { (own calculation for } \\
\text { Graz area) }\end{array}$ \\
\hline$\mu_{h}^{*} \geq 0$ & 0.44 & environmental damage parameter for group 2 ( own calculation ) \\
\hline$\mu_{c}^{*} \geq 0$ & 0.64 & environmental damage parameter for group 3 ( own calculation ) \\
\hline$\mu_{h} \geq 0$ & 0.64 & environmental damage parameter for group 4 ( own calculation ) \\
\hline$\varepsilon$ & 0.5 & $\begin{array}{l}\text { Armington elasticity of substitution between home production of } \\
\text { housing and imports (assumption) }\end{array}$ \\
\hline$S \geq 1$ & 1 & urban sprawl parameter (initial value) \\
\hline$R \geq 1$ & 1 & commuting transport cost factor (in the housing market) (initial value) \\
\hline$T \geq 1$ & 1 & (interregional) iceberg transport cost factor (initial value) \\
\hline$P>0$ & 1 & spatial policy parameter in hinterland (initial value) \\
\hline
\end{tabular}


Table 5: The exogenous and initial variables

\begin{tabular}{ccl}
\hline Variables & Value & \multicolumn{1}{c}{ Description } \\
\hline$L_{M}$ & 0.4 & manufacturing labour (centre) (initial value) \\
\hline$L_{M}^{*}$ & 0.4 & manufacturing labour (surroundings) (initial value) \\
$L_{H}=(1-\alpha) / 2$ & 0.1 & housing labour (centre) \\
$L_{H}^{*}=(1-\alpha) / 2$ & 0.1 & housing labour (surroundings) (initial value) \\
$\bar{L}=\bar{L}_{M}+\bar{L}_{H}=1$ & 1 & total labour (both regions) (initial value) \\
$0 \leq s \leq 1$ & 0.25 & $\begin{array}{l}\text { commuter share in the centre (own calculation for Graz area) } \\
\text { commuter share in the hinterland (own calculation for Graz } \\
0 \leq s^{*} \leq 1\end{array}$ \\
\hline
\end{tabular}

\subsubsection{The baseline scenario}

Let us now describe the baseline solution. Parameter $\lambda$ refers to the share of the labour force in the centre, so it corresponds to the sum of group 1 and group 4. On the other hand, the centre population of residents is made up of group 1 and group 3. Correspondingly, $(1-\lambda)$ equals the share of groups 2 and 3 , while the hinterland residential population is composed of group 2 and group 4 consumers.

The red (solid) line in Figure 3 depicts the (off-equilibrium) utility differentials for different values of $\lambda$, where $\lambda=1$ is $100 \%$. The green (transparent) line and the blue (dotted) line decompose the utility differential into differences in real income and environmental quality. Equilibrium values of $\lambda$ are marked where each of these lines crosses the x-axis. For the parameters given in Table 4, in equilibrium, i.e. where $u_{M}=u_{M}^{*}$, we find a centre labour force of $\lambda=0.52$. Due to the differences in environmental damage parameters across regions $\left(\mu_{c}<\mu_{h}^{*}\right)$, the obtained baseline scenario is thus a reference case with an asymmetric population distribution. In other words, in the baseline solution $52 \%$ of manufacturing workers are working in the centre and $48 \%$ in the hinterland.

The requirement that $u_{M}=u_{M}^{*}$ at $\lambda=0.52$ implies that the positive real wage differential $\left(w-w^{*}>0\right)$ just compensates the negative environmental quality differential $\left(Q-Q^{*}<0\right)$. Thus, the higher real wages in the centre just suffices to compensate for the lower environmental quality in the centre and there exists no pressure to move from the centre to the hinterland or vice versa. If the utility difference is positive (for values of $\lambda<0.52$ ), the share of manufacturing workers in the centre will increase and vice versa for values of $\lambda$ between 0.52 and 1 . 
Figure 3: Difference in utility $\left(u-u^{*}\right)$, real wage $\left(w-w^{*}\right)$ and environmental quality $\left(Q-Q^{*}\right)$ for different values of $\lambda$ with $S=1, R=1$ and $P=1$

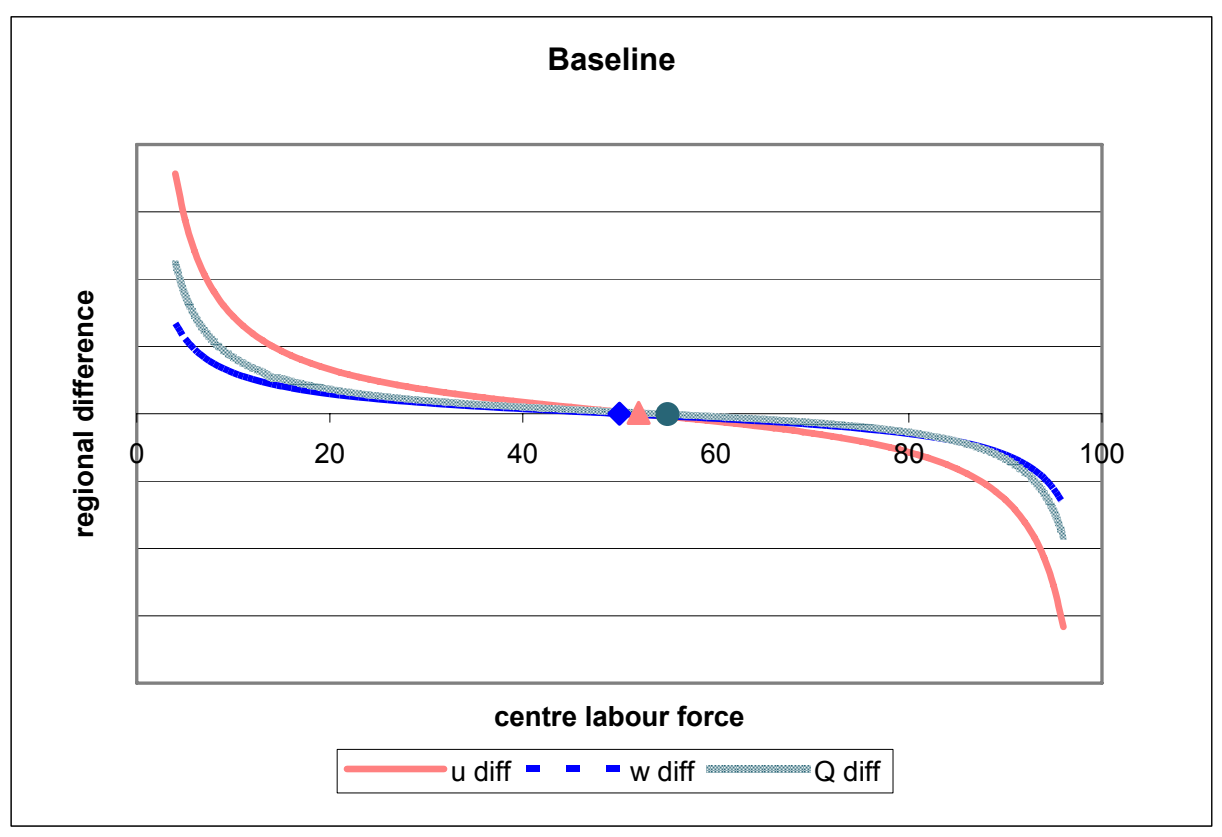

Note that the figure is limited to illustrating the labour force distribution. The shares of residents per region have yet been quantified; The corresponding share of the worker groups are $38.8 \%$ (of the total population) for group 1, 36.2\% for group $2,11.9 \%$ for group 3 and $13.2 \%$ for group 4 as given below by Table 6 . By adding groups 1 and 4 and groups 2 and 3, respectively, residents in the centre are 50.7\% of total population and $49.3 \%$ in the hinterland.

\subsection{The case of urban sprawl}

As outlined before, urban sprawl represents a dispersed settlement structure, with a rising number of commuters on the one hand and a growing share of outlying residents on the other. This combination entails that external effects in terms of transport-related pollution occur, leading to a degradation of environmental quality in both the centre and the surrounding region.

In order to introduce urban sprawl in our model, we increase the housing export share of the surroundings from initially $r_{c, 0}=0.25$ to 0.288 by setting parameter $S$ to $S=1.15$. By this means, we simulate an exogenous rise in commuters to the centre. The values of the changes in the population distribution between the two regions and the four consumer groups, respectively, which follow this parameter variation in our model, are given by Table 6 (right column). When urban sprawl is present, the number of group 3 commuters rises by $4.2 \%$, that of group 4 
commuters by $9.1 \%$. At the same time the hinterland population of residents increases moderately $(+0.8 \%)$, the hinterland labour force decreases slightly $(-0.6 \%)$, with reverse effects for the alternative region in each case. The change in $\lambda$, the centre labour force, is depicted by Figure 4 . The new equilibrium, where the per capita utility is identical for each region, levels out at $\lambda=0.523$.

Figure 4: Difference in utility $\left(u-u^{*}\right)$, real wage $\left(w-w^{*}\right)$ and environmental quality $\left(Q-Q^{*}\right)$ for different values of $\lambda$ with $S=1.15, R=1$ and $P=1$ (case of urban sprawl)

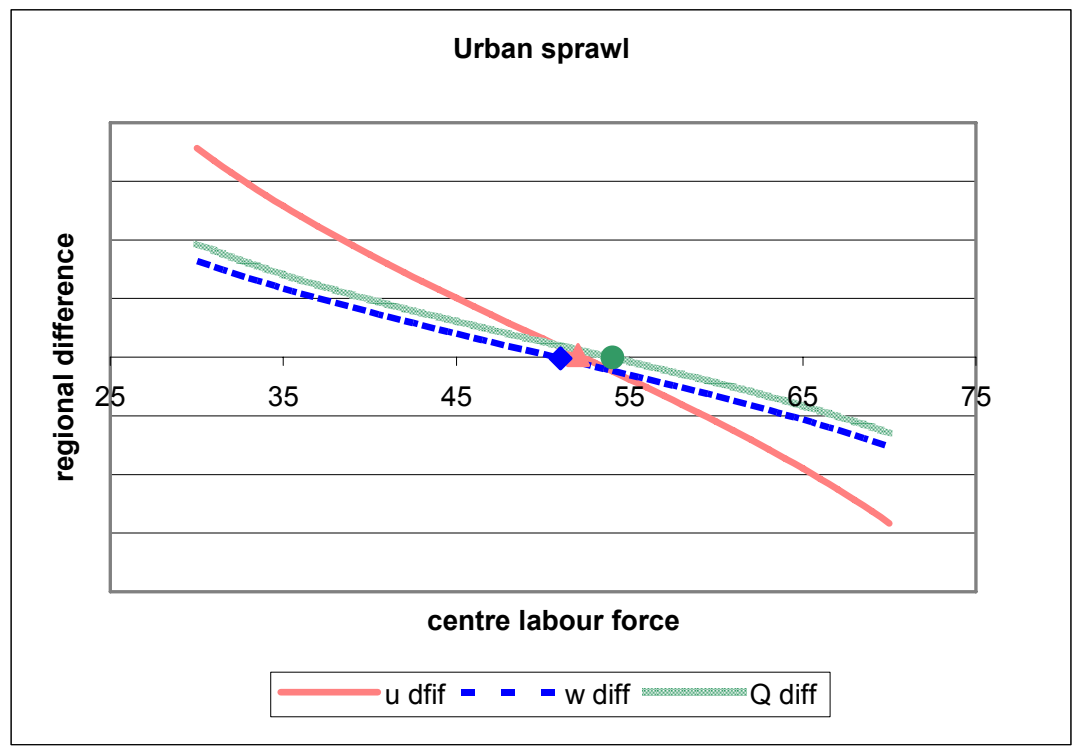

Table 6: The population distribution for the urban sprawl scenario (and changes compared to the baseline)

\begin{tabular}{|c|c|c|c|}
\hline & & Baseline & $\begin{array}{l}\text { Urban } \\
\text { Sprawl }\end{array}$ \\
\hline \multicolumn{4}{|l|}{ workforce per region } \\
\hline \multirow[t]{2}{*}{ centre $(=\lambda)$} & & 0,520 & 0,523 \\
\hline & $\Delta$ baseline & & $+0,6 \%$ \\
\hline \multirow[t]{2}{*}{ hinterland $(=1-\lambda)$} & & 0,480 & 0,477 \\
\hline & $\Delta$ baseline & & $-0,6 \%$ \\
\hline \multicolumn{4}{|l|}{ residents per region } \\
\hline \multirow[t]{2}{*}{ centre } & & 0,507 & 0,503 \\
\hline & $\Delta$ baseline & & $-0,8 \%$ \\
\hline \multirow[t]{2}{*}{ hinterland } & & 0,493 & 0,497 \\
\hline & $\Delta$ baseline & & $+0,8 \%$ \\
\hline \multicolumn{4}{|l|}{ non-commuters } \\
\hline \multirow[t]{2}{*}{ centre (= group 1) } & & 0,388 & 0,378 \\
\hline & $\Delta$ baseline & & $-2,6 \%$ \\
\hline \multirow[t]{2}{*}{ hinterland (= group 2) } & & 0,362 & 0,353 \\
\hline & $\Delta$ baseline & & $-2,5 \%$ \\
\hline \multicolumn{4}{|l|}{ commuters } \\
\hline \multirow[t]{2}{*}{ to hinterland (= group 3 ) } & & 0,119 & 0,124 \\
\hline & $\Delta$ baseline & & $+4,2 \%$ \\
\hline \multirow[t]{2}{*}{ to centre (= group 4 ) } & & 0,132 & 0,144 \\
\hline & $\Delta$ baseline & & $+9,1 \%$ \\
\hline
\end{tabular}




\section{Policy simulations}

Having described the reference case and the case of urban sprawl, we will now discuss the implementation of different policy measures. Based on the array of policy instruments described in Section 4, we select two specific instruments and describe their implementation in the model. We will study two measures: first, a pricing policy (congestion charge), and second, a spatial planning measure (such as the adaption of provincial land use regulation). These instruments are implemented in the model by changing the parameters $R$, the commuting cost factor, and $P$, the supply level of housing space in the hinterland. In doing so, we investigate the effectiveness of the policies to reach a previously determined environmental target value. I.e. we explore how stringently a pricing and a planning policy have to be implemented to completely internalise the transport related environmental externalities that prevail with urban sprawl, reflecting the optimization problem we are facing.

We will first discuss the impact of each measure on the equilibrium population shares (i.e. the labour force and residents per region) and the equilibrium share of the four worker groups and then go on to compare the local environmental impacts of these instruments. The last step is to compare the welfare effect of the two measures given the environmental target level is reached.

\subsection{Cordon pricing}

Cordon pricing is a mechanism that charges cars entering a high-activity area such as an urban core in order to relieve both inner-city congestion and cross-regional congestion caused by commuting. At the same time, the implementation of such a policy may result in an improved air quality.

We model cordon pricing by raising the commuting cost factor in the housing market $R$. In our model, this increase represents a change in transport costs in cross-regional commuting in both directions, a mobility behaviour that is required due to the disparity between the place of work and the location of residence. The level of commuting costs, where the external environmental effects of transport due to sprawl are internalized, is identified at $R=1.225$. For this policy value, Figure 5 depicts the regional differentials for levels of utility, real wage and environmental quality. The equilibrium level of $\lambda$ (which is the sum of group 1 and group 4) slightly increases relative to the case of urban sprawl. 
The sensitivity of $R$ with respect to the change in environmental quality (relative to the baseline) in the centre and the hinterland as well as the effect for both regions in total are illustrated in Figure 6. The figure also shows that at the stringency level of $R=1.225$, the environmental effects are overcompensated in the hinterland and vice versa in the centre (for exact values see Table 8 ).

Figure 5: Difference in utility $\left(u-u^{*}\right)$, real wage $\left(w-w^{*}\right)$ and environmental quality $\left(Q-Q^{*}\right)$ for different initial values of $\lambda$ with $S=1.15, R=1.225$ and $P=1$ (cordon pricing policy)

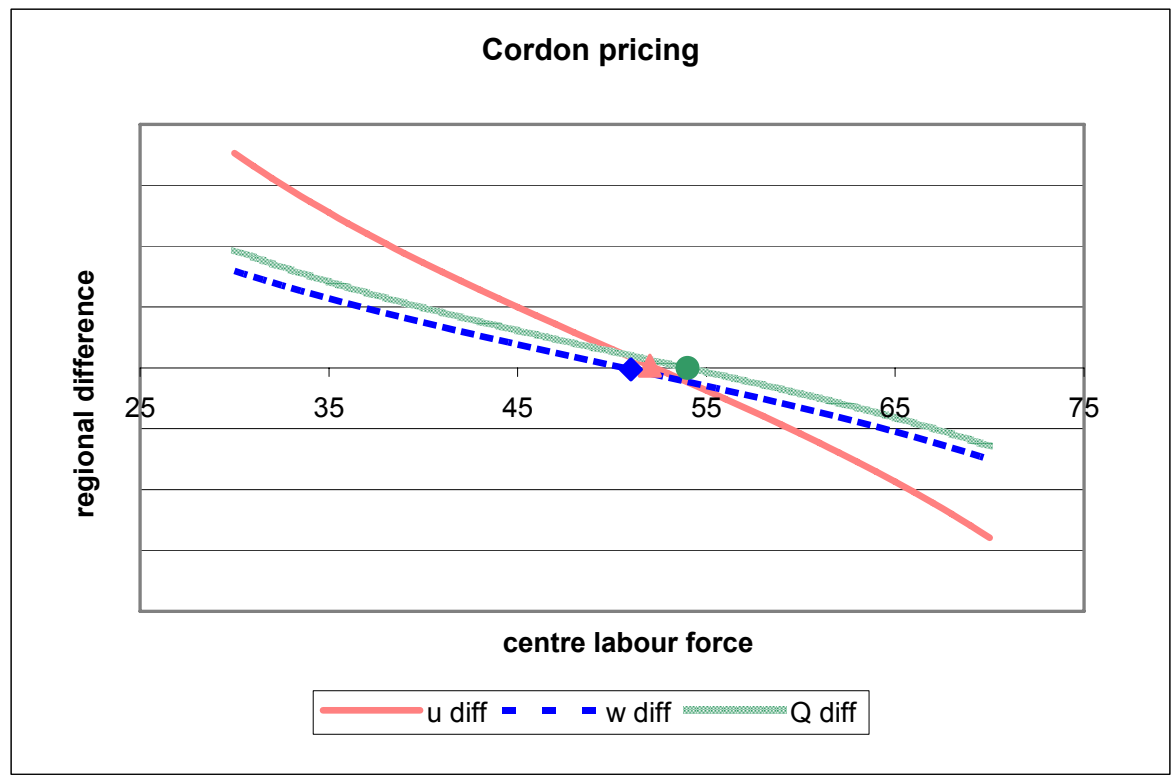

Figure 6: Sensitivity of the change in $\mathrm{PM}_{10}$ emissions (compared to the baseline) with respect to the cordon pricing policy parameter $R$.

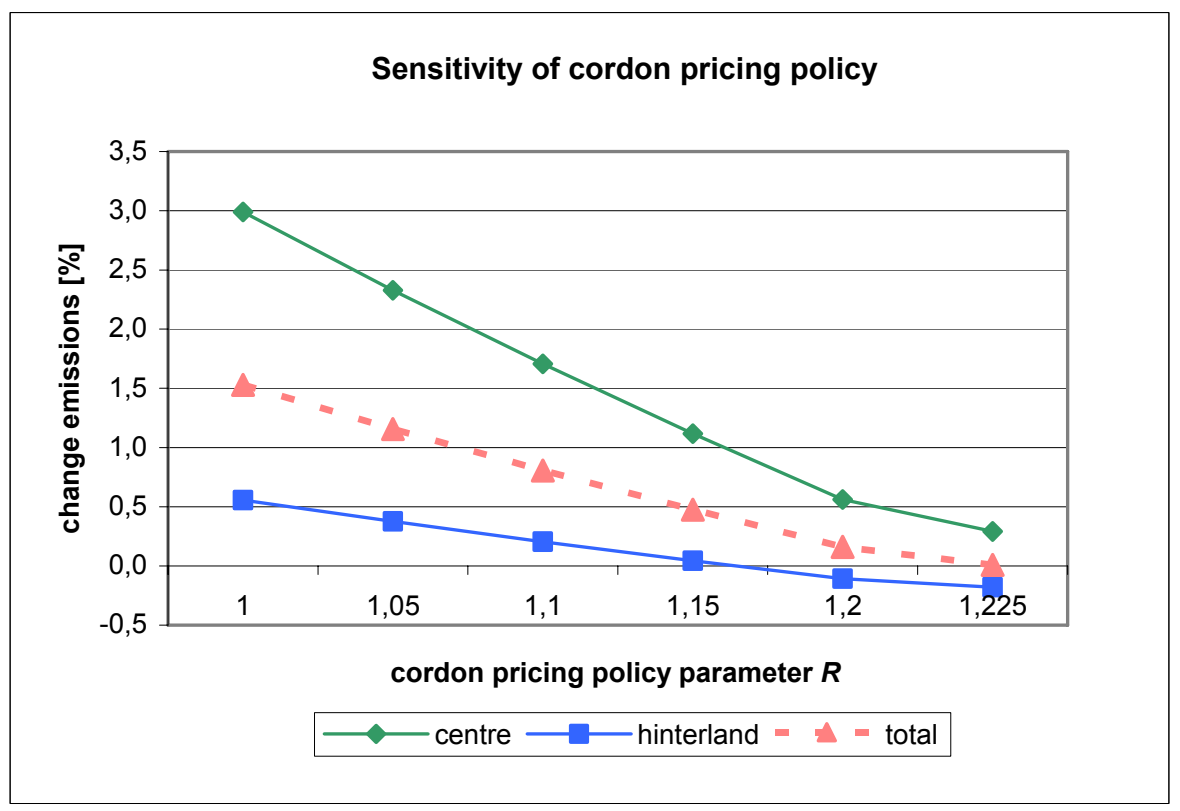




\subsection{Spatial planning}

Spatial planning in the hinterland aims at denser housing development, addressing the prevention of excessive urban sprawl. Ideally, with denser housing the environmental impact per capita in the overall region is reduced, enabling public transport services and shorter distances to be traveled. These effects results in lower pollution feedback impact on ever rising urban sprawl.

As a very first step towards such a policy, we restrict the housing supply in the peripheral region. We could think of instruments such as charges for the provision of public infrastructure (aimed at idle building land in central locations), the adoption of land use regulation or the restructuring of funding for residential property. The implemented restriction helps us to find out about partial effects of an overall planning measure.

In order to integrate the policy in our model, we implement a change in the supply level of housing space in the hinterland $P$. More specifically, we reduce production inputs in hinterland housing. We let parameter $P$ decrease to $P=0.66$, reflecting a restriction of housing space in the hinterland at a stringency level that totally internalizes the environmental externalities from urban sprawl. While cordon pricing gradually improved the environmental quality in both regions, we find from Figure 8 that a spatial planning measure in the hinterland with a stringency of $P=0.66$ has varying effects on the centre and the hinterland emissions, with a strong improvement in environmental quality in the centre and degradation in the hinterland (compared to the baseline), summing up to a zero total change in quality (full internalization).

For the full internalization level $P=0.66$, Figure 7 depicts the regional differentials for levels of utility, real wage and environmental quality for different values of $\lambda$. There is a moderate increase $(+4.4 \%)$ in the equilibrium level for $\lambda$ to a value of $\lambda=0.546$. The sensitivity of $P$ with respect to the change in environmental quality in the centre and the hinterland as well as the effect for both regions in total are illustrated in Figure 8. 
Figure 7: Difference in utility $\left(u-u^{*}\right)$, real wage $\left(w-w^{*}\right)$ and environmental quality $\left(Q-Q^{*}\right)$ for different initial values of $\lambda$ with $S=1.15, R=1$ and $P=0.66$ (spatial planning policy)

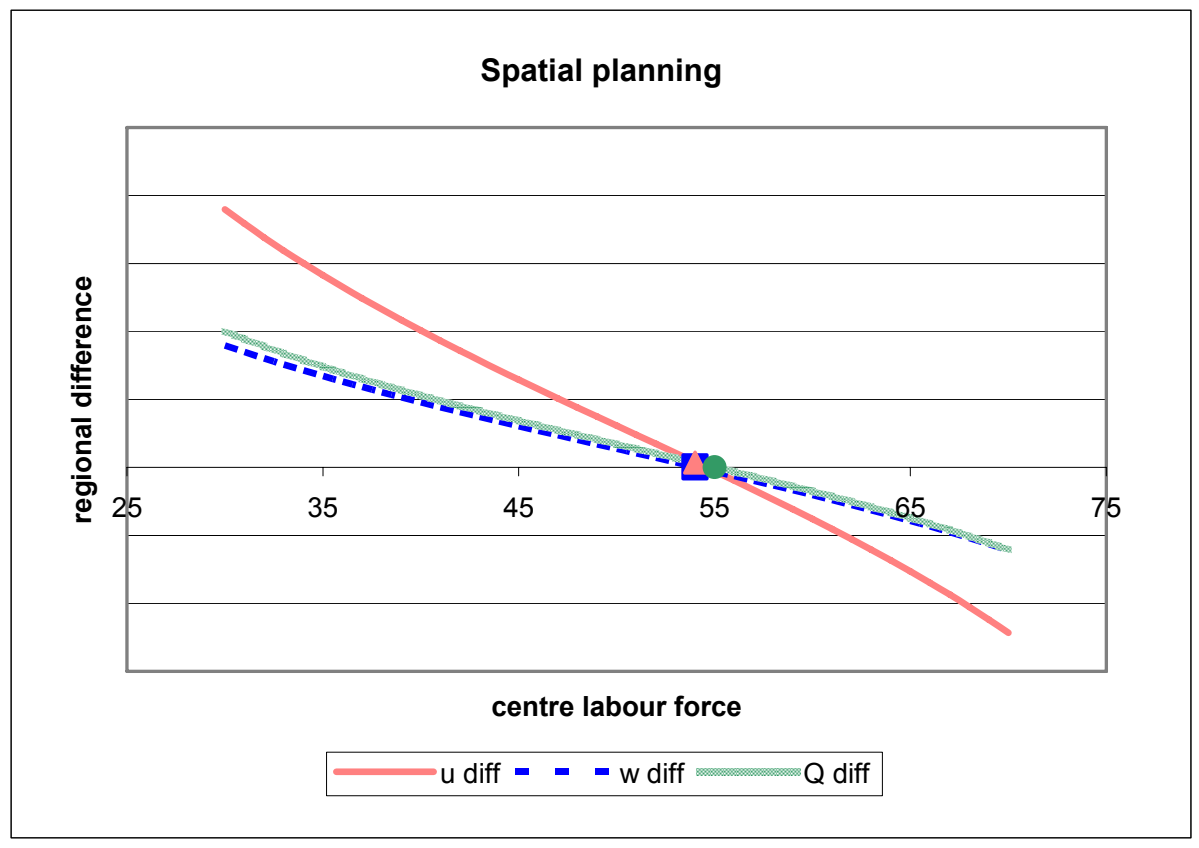

Figure 8: Sensitivity of the change in $\mathrm{PM}_{10}$ emissions (compared to the baseline) with respect to the spatial planning policy parameter $P$.

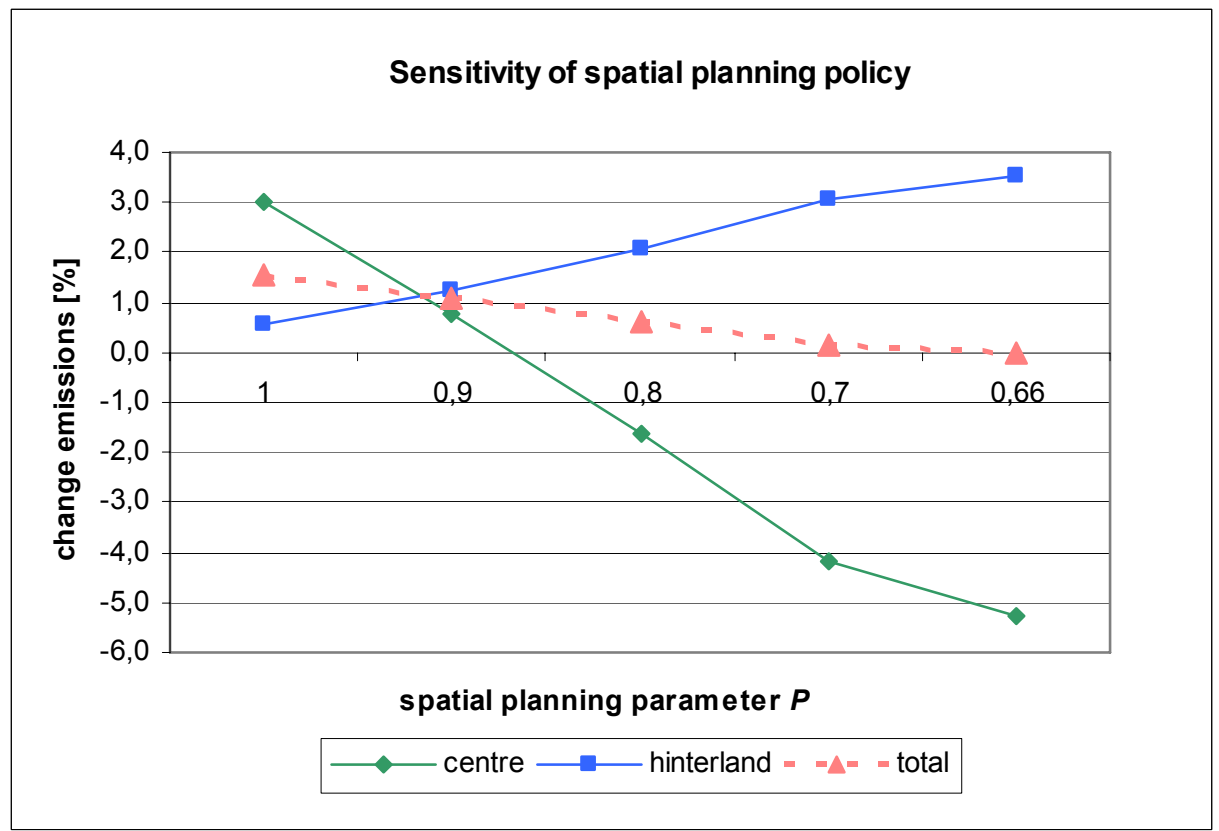




\subsection{Effects on location of residence and commuting}

The instrument of cordon pricing affects interregional commuter flows in both directions i.e. flows form the centre to the hinterland region and vice versa. Thus, this instrument combats the rise in commuters that has been induced by urban sprawl. As shown in Table 7, group 3 and group 4 commuters decline in numbers relative to the urban sprawl scenarios (-6.5\% and $-6.9 \%)$, which is compensated by a rise in intraregional commuters groups (group 1 and group 2). Moreover, the number of residents in the hinterland falls slightly $(-0.4 \%)$, indicating that consumers start to move back to the centre to live in the region where they also work.

Table 7: The population distribution for the policy scenarios (and changes compared to the urban sprawl scenario)

\begin{tabular}{|c|c|c|c|c|}
\hline & & $\begin{array}{l}\text { Urban } \\
\text { Sprawl }\end{array}$ & $\begin{array}{l}\text { Cordon } \\
\text { Pricing }\end{array}$ & $\begin{array}{c}\text { Spatial } \\
\text { Planning }\end{array}$ \\
\hline \multicolumn{5}{|l|}{ workforce per region } \\
\hline \multirow[t]{2}{*}{ centre $(=\lambda)$} & & 0,523 & 0,523 & 0,546 \\
\hline & $\Delta$ urban sprawl & & $+0,0 \%$ & $+4,4 \%$ \\
\hline \multirow[t]{2}{*}{ hinterland $(=1-\lambda)$} & & 0,477 & 0,477 & 0,454 \\
\hline & $\Delta$ urban sprawl & & $+0,0 \%$ & $-4,8 \%$ \\
\hline \multicolumn{5}{|l|}{ residents per region } \\
\hline \multirow[t]{2}{*}{ centre } & & 0,503 & 0,505 & 0,581 \\
\hline & $\Delta$ urban sprawl & & $+0,4 \%$ & $+15,5 \%$ \\
\hline \multirow[t]{2}{*}{ hinterland } & & 0,497 & 0,495 & 0,419 \\
\hline & $\Delta$ urban sprawl & & $-0,4 \%$ & $-15,7 \%$ \\
\hline \multicolumn{5}{|l|}{ non-commuters } \\
\hline \multirow[t]{2}{*}{ centre (= group 1 ) } & & 0,378 & 0,389 & 0,430 \\
\hline & $\Delta$ urban sprawl & & $+2,9 \%$ & $+13,8 \%$ \\
\hline \multirow[t]{2}{*}{ hinterland (= group 2) } & & 0,353 & 0,362 & 0,303 \\
\hline & $\Delta$ urban sprawl & & $+2,5 \%$ & $-14,2 \%$ \\
\hline \multicolumn{5}{|l|}{ commuters } \\
\hline \multirow[t]{2}{*}{ to hinterland (= group 3 ) } & & 0,124 & 0,116 & 0,151 \\
\hline & $\Delta$ urban sprawl & & $-6,5 \%$ & $+21,8 \%$ \\
\hline \multirow[t]{2}{*}{ to centre (= group 4 ) } & & 0,144 & 0,134 & 0,116 \\
\hline & $\Delta$ urban sprawl & & $-6,9 \%$ & $-19,4 \%$ \\
\hline
\end{tabular}

In order to analyse the impacts of the spatial planning instrument in the hinterland, we have to take account of the fact that this measure mainly affects the groups of those residents who live in the peripheral region. Overall, restricting the supply of housing has very strong effects on the population distribution. Outstanding are the dramatic fall in hinterland residents $(-15.7 \%)$ and its corresponding rise for the 
centre population $(+15.5 \%)$. Thus, the restriction of housing by setting the full internalization level $P=0.66$ operates strongly on the consumers' housing decision, driving up hinterland housing prices and reducing the incentive to resettle to the outer region. Effects regarding the labour force are weaker, yet still quite strong $(+4.4 \%$ for the centre and $-4.8 \%$ for the hinterland). The impact on the hinterland residential population corresponds to the considerable fall in the size of those consumer groups, who live in the hinterland, namely group $2(-14.2 \%)$ and group 4 $(-19.4 \%)$. Analogously, we find an incentive to live in the centre region; the remaining groups (groups 1 and 3$)$ thus undergo a significant rise in size $(+13.8 \%$ and $+21.8 \%)$.

\subsection{Environmental impacts}

Based on changes settlement structures and commuting flows we evaluate the environmental impacts of the implemented policies. For this reason let us have a look at the share of cross-regional commuters (left graphics in Figure 9) and the population per region (right graphics) in each scenario again.

Figure 9: Commuting flows (group 3 and group 4) and settlement structure (centre and hinterland residents) under different scenarios.

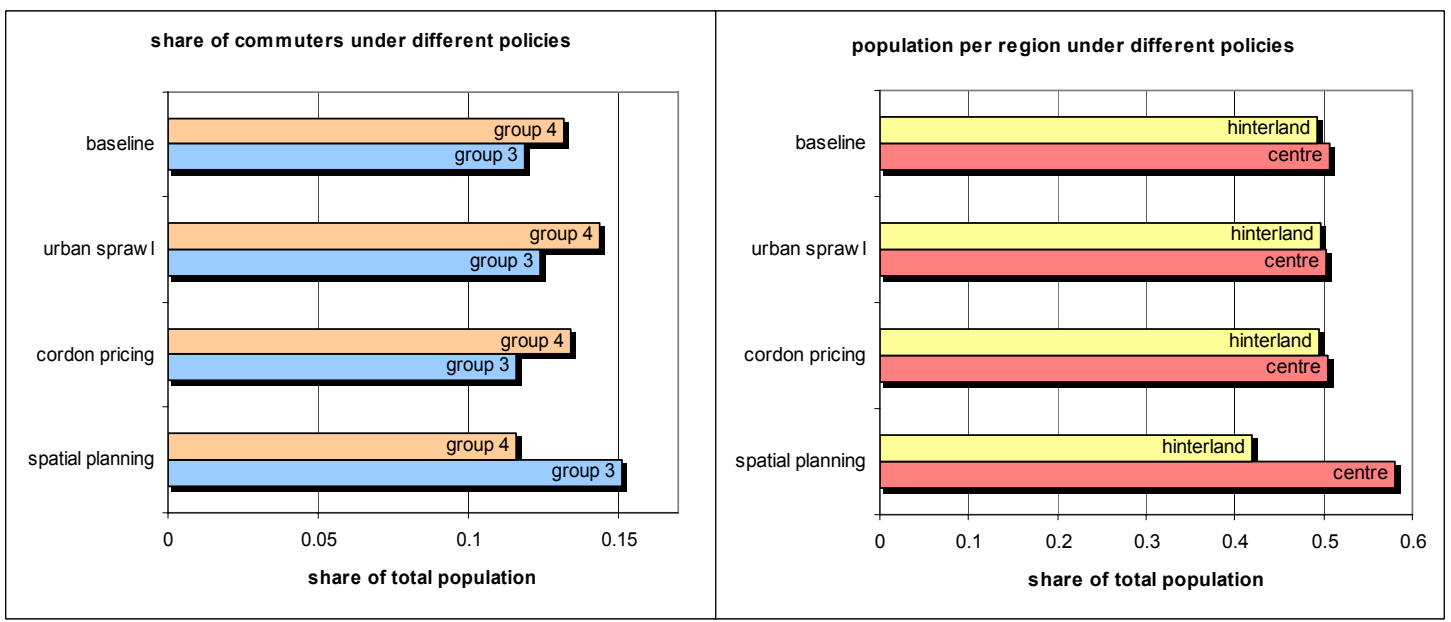

Recall that we assumed pollution to be caused by passenger transport only, prompted to a large part by commuting residents. Moreover, from Section 5 we know that transport related emissions are different for each commuter group due to differences in modal split and vehicle miles travelled. The highest impacts from commuting stem from cross-regional trips (groups 3 and 4), where distances are longest and car dependency is high. They are followed by commuting trips within 
the hinterland, mainly because group 2 is characterized by a low share of public transport. By contrast, trips within the centre region are less car dependent and do not involve substantial distances to be travelled; so the impact is lowest within group 1. Due to our assumption of constant emission factors per trip and group, environmental effects are linear in the number of workers.

It is important to take into account the type of pollutant when aggregating environmental impacts. While for global pollutants such as $\mathrm{CO}_{2}$ the location of emission is irrelevant, for local pollutants like $\mathrm{PM}_{10}$ the location of emission is essential. In this vein, it is equally important to know where pollutants such as particulate matter accumulate (i.e. the ambient level) and where emissions are originally caused. In order to capture that difference, we report environmental effects per region and for both regions in total in Table $8 .^{7}$

Both cordon pricing and spatial planning are imposed such that they lead to an improved aggregated environmental quality over both regions (full internalization level). For each of the instruments we find the following. The improved environment induced by cordon pricing stems from a decrease in the number of cross-regional commuters (groups 3 and 4) whose emission factors are highest. Table 4 reports on the respective environmental damage parameters, i.e., $\mu_{3}=\mu_{4}=0.64$ for groups 3 and 4 . The reduction in interregional commuters suggests that emissions of pollutants will be mitigated because vehicle miles travelled decrease, and there is a lower car dependency in the overall region. As a consequence, cordon pricing improves the level of environmental quality in both regions, with a stronger effect in the centre region; here the ambient level of $\mathrm{PM}_{10}$ declines by $2.6 \%$ relative to a situation of urban sprawl. For both regions in total, emissions are mitigated by $1.5 \%$ compared to urban sprawl, which corresponds to a complete internalization of mobility related externalities, thereby restoring the reference level of environmental quality (baseline). The values are reported in Table 8.

7 Recall that in order to calculate the pollution levels per region we assumed group 3 to contribute to the hinterland level and group 4 to the centre level. Moreover, we generally assume 10 commuting trips per week and commuter and 42 weeks per year. 
Table 8: $\mathrm{PM}_{10}$ emissions for the policy scenarios cordon pricing and spatial planning (and changes compared to the baseline and the urban sprawl scenario)

\begin{tabular}{|c|c|c|c|c|c|}
\hline & & Baseline & $\begin{array}{l}\text { Urban } \\
\text { Sprawl }\end{array}$ & $\begin{array}{l}\text { Cordon } \\
\text { Pricing }\end{array}$ & $\begin{array}{l}\text { Spatial } \\
\text { Planning }\end{array}$ \\
\hline & & $\mathbf{P M}_{10}$ & $\mathrm{PM}_{10}$ & $\mathrm{PM}_{10}$ & $\mathrm{PM}_{10}$ \\
\hline & & [tons/year] & [tons/year] & [tons/year] & [tons/year] \\
\hline \multicolumn{6}{|c|}{ effect per region } \\
\hline \multirow[t]{3}{*}{ centre } & & 153,366 & 157,950 & 153,813 & 145,274 \\
\hline & $\Delta$ urban sprawl & & & $-2.6 \%$ & $-8.0 \%$ \\
\hline & $\Delta$ baseline & & $+3.0 \%$ & $+0.3 \%$ & $-5.3 \%$ \\
\hline \multirow[t]{3}{*}{ hinterland } & & 230,009 & 231,285 & 229,595 & 238,115 \\
\hline & $\Delta$ urban sprawl & & & $-0.7 \%$ & $+3.0 \%$ \\
\hline & $\Delta$ baseline & & $+0.6 \%$ & $-0.2 \%$ & $+3.5 \%$ \\
\hline \multirow[t]{3}{*}{ total effect } & & 383,375 & 389,235 & 383,408 & 383,389 \\
\hline & $\Delta$ urban sprawl & & & $-1.5 \%$ & $-1.5 \%$ \\
\hline & $\Delta$ baseline & & $+1.5 \%$ & $+0.0 \%$ & $+0.0 \%$ \\
\hline
\end{tabular}

The spatial planning measure reduces overall pollution by counteracting outmigration. The general reduction in transport related pollutants is due to less residents in the hinterland (i.e., a decline in group 2 and group 4 workers), via the induced rise in hinterland housing prices. However, the reduction in housing supply has now also induced new transport by a considerable rise in residents who commute from the centre to the hinterland (group 3 increases). For spatial planning, the ambient level of $\mathrm{PM}_{10}$ thus decreases considerably in the centre $(-8 \%)$, as shown in Table 8 , and rises moderately in the hinterland (+3\%). Taking the effects for the centre and the hinterland together, the overall level of pollutants equals the baseline level. The implemented policy has therefore internalised the transport related externalities induced by urban sprawl.

\subsection{Effects on utility levels}

As a first step towards a welfare analysis, we explore the level and composition of per capita utility levels of the manufacturing workers (i.e. those residents who are mobile between regions in the model). By definition of an equilibrium, the per capita utility per region is balanced for the centre and the hinterland for each policy scenario. The level of per capita utility, though, varies across scenarios as well as the combination of manufacturing goods $M$ and environmental quality $Q$. Figure 10 shows the respective utility levels.

While per capita utility levels are slightly decreasing with urban sprawl $(-0.2 \%$ compared to the baseline), they are moderately lower with cordon pricing $(-0.6 \%)$ 
and considerably with spatial planning (-3.3\%) (both compared to the case of urban sprawl). From that we conclude that the simulated restriction of housing supply in the hinterland (via planning) represents a major intervention and has significant effect on utility and welfare levels, respectively. We also conclude, however, that the external effect from transport is not modelled adequately for the moment. This can be seen from the hardly changing welfare level induced by sprawl (relative to the baseline).

Moreover, the contribution of manufacturing goods $M$ to utility decreases in both regions in both policy scenarios, yet to a stronger degree in case of a planning measure. On the other hand, the contribution of environmental quality $Q$ to utility differs: Cordon pricing operating symmetrically increases the contribution of $Q$ in centre and periphery, whereas it falls in the centre and rises in the hinterland for the planning measure, reflecting the one-sided effect of this policy.

Figure 10: Per capita utility of manufacturing workers from manufacturing goods $M$ and environmental quality $Q$ for the centre $(c)$ and the hinterland $(h)$ region and for each scenario

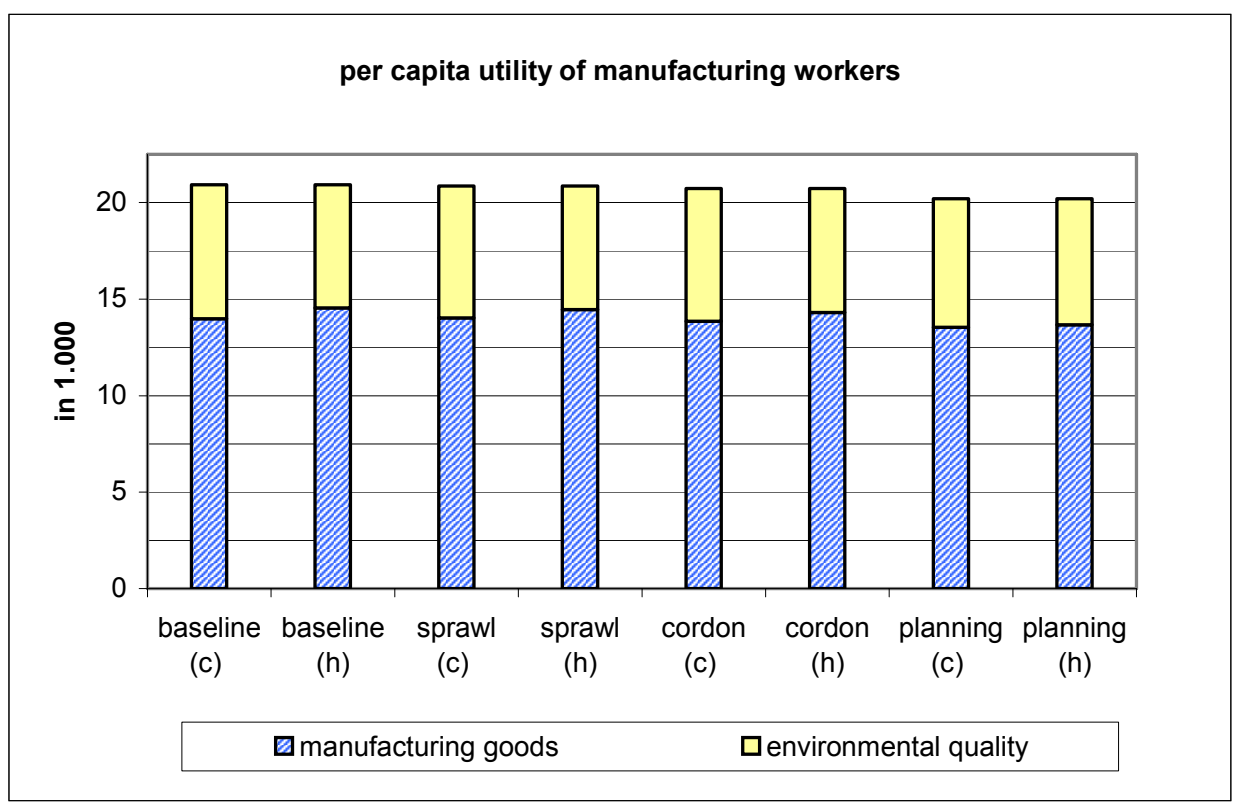





\section{Summary and conclusions}

The aim of the project SPACON+ was to explain the driving forces for the suburbanisation of urban areas and its link to commuting and environmental concerns. First we extended a standard core-periphery model to integrate housing and environmental concerns; then the theoretical framework was expanded to the empirical domain. With this model, we are able to analyse the main determinants of urban sprawl and policy instruments to address its environmentally harmful implications.

Since the number of commuters and non-commuters determine the region-specific level of environmental quality and since environmental quality contributes to household utility, environmental quality affects the location decision of households in the long run. If the environment differs across regions, a lower environment has to be compensated for by higher consumption quantities of the manufactured and/or housing commodity. Moreover, since housing production is fixed in quantitative terms yet workers are mobile across regions, the arising changes in housing prices induce a fraction of the population to resettle to the cheaper region. A spatial equilibrium thus implies that the regional difference in real income is compensated by the difference in environmental quality.

In addition to a baseline scenario, we construct an urban sprawl scenario to reflect the present trend in many urban agglomerations. Different environmental damage parameters for different types of commuting imply an asymmetric population distribution in the long term, with a larger fraction of residents located in the region with lower overall environmental impacts. If the strength of consumers' environmental preferences increases, this population share rises, too, reinforcing the dispersed population distribution.

In our policy analysis, we first investigate the effects of a congestion charge in order to reduce the number of cross-regional commuters. Second, we look at the consequences of a spatial planning instrument such that zoning plans in the hinterland are more stringent, i.e. reducing the effective housing supply in the hinterland. We identify the stringency levels necessary to fully internalize the environmental consequences of urban sprawl relative to the baseline level (without sprawl). In evaluating these policy options we find the following.

Both instruments generally reduce urban sprawl, though they do so through different channels. Cordon pricing curbs sprawl by addressing cross-regional commuters. By contrast, a planning measure is capable of reducing the degree of urban sprawl due to the arising rise in property prices in the addressed region. 
Moreover, the shift between the consumer groups - both in magnitude and direction - is different for the two policies. While cordon pricing operates symmetrically and addresses residents who commute between the regions, spatial planning has ambiguous effect for the two regions. In particular, with cordon pricing the direction of change is the same for non-commuters on the one hand and commuters on the other hand. Implementing a spatial planning instrument, however, leads to similar effects for workers who live in the region addressed by the policy measure.

Regarding environmental impacts, both policies lead to desirable effects for the overall region, yet with different effects for ambient levels of $\mathrm{PM}_{10}$ per region. The reason is that cordon pricing most strongly curbs the total number of cross-regional commuters, driving long distances with car dependent modal shares, which improves the environment. On the other hand, instruments restricting housing supply in the hinterland do so by applying to residents who commute to the centre and to those who drive long distances within the hinterland region. Hence, from a regional perspective, the pricing policy is connected to favorable emission reductions in both regions, whereas the hinterland planning measure has ambiguous results from an environmental perspective (with an improvement for the centre, but a degradation for the hinterland).

Aiming at the internalization of the environmental effects of urban sprawl, it becomes clear that policy measures relevant for the development of the transport sector should also address the spatial distribution of economic activities rather than transport flows per se. Emission impacts from passenger transport can thus be mitigated by addressing the distribution of workplaces and residences and, accordingly, by steering the number of commuters between regions. The regional welfare results with regard to the contribution of environmental quality to utility reflect the basic characteristics of the two policy instruments with respect to regional symmetry, i.e. direction, and magnitude of their effects. 


\section{References}

Alonso, W. (1964), Location and Land Use: Towards a General Theory of Land Rent. Harvard University Press, Cambridge, Mass.

Arnott, R., Hochman, O., Rausser, G.C. (2004), Pollution and land use. Working Paper No. 04-14. Department of Economics, Ben Gurion University.

Baldwin, R., Forslid, R., Martin, P., Ottaviano, G., Robert-Nicoud F. (2003), Economic Geography and Public Policy. Priceton: Priceton University Press.

Cerveny, M., Tretter, H. (2003), Energie- und klimaschutzrelevante Bestimmungenin den Bauordnungen und Wohnbauförderungen, Austrian Energy Agency, http://www.energyagency.at/service/wbf.htm (Oct 24, 2006)

Dixit, A.K., Stiglitz, J.E. (1977), Monopolistic competition and optimum product diversity, American Economic Review 67: 297-308.

Eckey, H.-F., Kosfeld, R. (2004), New Economic Geography. Discussion Papers in Economics 65/04, University of Kassel, Institute of Economics, Kassel.

Environmental Protection Agency (EPA) (1998), Transportation Control Measures: Congestion Pricing. TRAQ Technical Overview. EPA420-S-98-004.

Eppink, F.V., Withagen, C.A. (2006), Spatial patterns of biodiversity conservation in a multiregional general equilibrium model. Paper presented at 3rd World Conference for Environmental and Resource Economists, July 2006, Kyoto/Japan.

Friedl B., Burian E., Molitor R., Steininger K. (2000), Environmentally Sustainable Transport Case Study Austria, Final Report, BMLFUW, Vienna.

Fujita, M., Krugman, P., Venables, A.J. (1999), The Spatial Economy: Cities, Regions, and International Trade. MIT Press, Cambridge, MA.

Fujita, M., Mori, T. (2005), Frontiers of the New Economic Geography. Papers in Regional Science 84(3): 377-405.

Helpman, E. (1998), The size of regions, in Pines, D., E. Sadka and I. Zlcha (eds). Topics in Public Economics: Theoretical Analysis. Cambridge University Press, Cambridge, 34-54.

Käfer A., Steininger K., Axhausen K., Burian E., Clees L., Fritz O., Gebetsroither B., Grubits C., Huber P., Kurzmann R., Molitor R., Ortis G., Palme G., Peherstorfer H., Pfeiler D., Schönfelder S., Siller K., Streicher G., Thaller O., Wiederin S. and Zakarias G. (forthcoming), Verkehrsprognose Österreich 2025+, Prognose im Auftrag von BMVIT, ASFINAG, ÖBB, SCHIG, Wien.

Krugman, P. (1991), Increasing returns and economic geography. Journal of Political Economy 99: 483-499.

Marrewijk, C. van (2005), Geographical economics and the role of pollution on location. Discussion paper TI 2005-018/2, Tinbergen Institute, AmsterdamRotterdam.

Murata, Y., Thisse, J.F. (2005), A simple model of economic geography à la Helpman-Tabuchi. Journal of Urban Economics 58: 137-155. 
OECD (2005), Decoupling Transport Impacts and Economic Growth, Case Study Austria, Final Report.

Ottaviano, G., Puga, D. (1998), Agglomeration in the Global Economy: A Survey of the 'New Economic Geography'. World Economy 21 (6): 707-731.

Ottaviano, G., Tabuchi, T., Thisse, J.F. (2002), Agglomeration and trade revisited. International Economic Review 43: 409-436.

Pflueger, M., Suedekum, J. (2006), Integration, Agglomeration and Welfare, Working Paper, revised version, Feb. 2006.

Prettenthaler, F., Steininger, K.W., Stocker, A., Zakarias, G. (2002), Environmentally Counterproductive Support Measures im Bereich Verkehr. Study on behalf of the Federal Ministry of Agriculture, Forestry, Environment and Water Management, Austria.

Puwein, W. (2000), Transportkosten in der österreichischen Wirtschaft. WIFO, Wien.

Quaas, M., Lange, A. (2007), Economic Geography and the Effect of Environmental Pollution on Agglomeration, The B.E. Journal of Economic Analysis \& Policy 7(1), Article 52.

Samuelson, P.A. (1952), The transfer problem and transport costs. Economic Journal 62: 278-304

Schleicher, S., Steininger, K., Stockreiter, M., Streicher, W. (2006), Innovation und Klima, Study on behalf of the Federal Ministry of Economics and Labour Affairs, the Austrian Federal Chambre of Commerce, the Austrian Industrial Association, and the Association of Electric Utilities, Vienna.

Statistik Austria (2006), Verbrauchsausgaben 2004/05. Hauptergebnisse der Konsumerhebung. Wien.

Steininger, K. W., Gobiet, W., Binder, C., Friedl, B., Gebetsroither, B., Niederl, A., Kriebernegg, G., Omann, I., Seebauer, S. (2005), Technologien und Wirkungen von PKW-Road Pricing im Vergleich. Report No 1-2005, Wegener Center for Climate and Global Change, Univ. of Graz

Steininger, K.W., Berdnik, S., Gebetsroither, B., Getzner, M., Hausberger, S., Hochwald, J. (2007), Klimaschutz, Infrastruktur und Verkehr. Studie im Auftrag der Arbeiterkammer Wien, Abteilung Umwelt und Verkehr. Report No 15-2007, Wegener Center for Climate and Global Change, Univ. of Graz.

Suedekum, J. (2006), Agglomeration and regional costs of living. Journal of Regional Science 46(3): 529-543.

Tabuchi, T. (1998), Urban agglomeration and dispersion: A synthesis of Alonso and Krugman. Journal of Urban Economics 44: 333-35.

Tabuchi, T., Thisse, J.F. (2006), Regional Specialization, Urban Hierarchy, and Commuting Costs. International Economic Review 47(4): 1295-1317.

Umweltbundesamt (UBA) (2007), Austria's Annual Greenhouse Gas Inventory 1990-2005, Submission under Decision 280/2004/EC, Vienna.

Verhoef, E. (1996), The Economics of Regulating Road Transport. Cheltenham: Edwar Elgar.

Verhoef, E.T., Nijkamp, P. (2002), Externalities in urban sustainability: Environmental versus agglomeration externalities in a general spatial 
equilibrium of a single-sector monocentric industrial city. Ecological Economics 40: 157-179.

Verhoef, E.T., Nijkamp, P. (2003), Externalities in the urban economy. Discussion paper TI 2003-078/3, Tinbergen Institute, Amsterdam-Rotterdam.

von Thünen, J.H. (1826), Der Isolierte Staat in Beziehung auf Landschaft und Nationalökonomie. Hamburg. English translation: Hall, P. (ed.), translated by Wartenberg, C.M. (1966). von Thünen's Isolated State. Pergamon Press, Oxford.

Weber, G., Griesser, H. (2006), A discourse on urban sprawl in the county of Styria/Austria. Workshop Raumplanung Steiermark, „Zersiedeln wir die Steiermark“, 17 May, 2006.

Weibull, J.W. (1995), Evolutionary Game Theory. Cambridge, MA: MIT Press.

Yoshino, Y. (2004), Migration, agglomeration and pollution: an economic geography model of trade and the environment. Working Paper. Department of Economics, University of Virginia. 



\section{Appendix}

\section{A.1 Stability of the symmetric equilibrium for identical regions}

For the derivation of $d u_{M} / d \lambda$ as given in equation (34), we make use of the fact that around the symmetric equilibrium all endogenous variables are identical in both regions. Thus, the values $\lambda=1 / 2, w_{M}+p_{K} c_{M}=y_{M}=1$ and $p_{H}=1$ hold in both the centre and the hinterland. This yields $Y=1 / 2, G^{1-\sigma}=\left(1+T^{1-\sigma}\right) / 2$, $Z=\left(1-T^{1-\sigma}\right) /\left(2 G^{1-\sigma}\right), L_{M}=\alpha / 2$ and $K_{M}=1 / 2 ;$ the variable $Z$ follows as an index of transport costs defined as $Z \equiv\left(1-T^{1-\sigma}\right) /\left(1+T^{1-\sigma}\right)$ with $0 \leq Z \leq 1 .^{8}$ The second important point is that any change in a variable in one region is matched by an equal but opposite sign change in the other region. Thus, we let $d G=-d G^{*}$, $d L_{M}=-d L_{M}^{*}, d y_{M}=-d y_{M}^{*}, d Y=-d Y^{*}$, and $d p_{H}=-d p_{H}^{*}$. Furthermore we let the environmental impact factors be equal across regions, i.e. $\mu_{c}=\mu_{h}^{*}$ and $\mu_{h}=\mu_{c}^{*}$, which finally gives $d u_{M} / d \lambda=-d u_{M}^{*} / d \lambda$. Then, the total differential of the per capita utility, using the above indicated values, is

$$
\begin{aligned}
d u_{M} & =d \omega+\delta d Q= \\
& =G^{-\alpha}\left(R^{1-\beta}\right)^{-(1-\alpha)} \Omega\left(d y_{M}-\alpha \frac{d G}{G}-d p_{H}(1-\alpha)(2 \beta-1)\right)+ \\
& +\delta \frac{2 d p_{H} e^{\frac{-\beta R \mu_{c}-(1-\beta) \mu_{h}}{\beta(R-1)+1}} R(1-\beta)\left(\mu_{c}-\mu_{h}\right)}{(\beta(R-1)+1)^{2}}
\end{aligned}
$$

with $\Omega=\alpha^{\alpha}(1-\alpha)^{1-\alpha}\left(\beta^{\beta}(1-\beta)^{1-\beta}\right)^{1-\alpha}$. Totally differentiating equations (19) to (22) yields

$$
\begin{aligned}
& d y_{M}=\frac{2 Z d Y}{\sigma}+Z \frac{(\sigma-1)}{\sigma} \frac{d G}{G} \\
& d Y=\alpha d \lambda+\frac{\alpha d y_{M}+(1-\alpha) d p_{H}}{2} \\
& \frac{d G}{G}=\frac{2 Z}{1-\sigma} d \lambda+Z d y_{M} \\
& d p_{H}=2 d Y \frac{\beta(1+R)-1}{R}
\end{aligned}
$$

\footnotetext{
${ }^{8}$ When there are no transport costs, i.e. $T=1$ (free trade), the index $Z=0$. When, on the other hand, transport costs are prohibitively high, i.e. $T \rightarrow \infty$ (trade is impossible), $Z=1$.
} 
In order to find out whether $\lambda=1 / 2$ is a stable distribution for specific parameter values, we substitute equations (A2)-(A5) into (A1), resulting in the change in per capita utility caused by a relocation of residents:

$$
\begin{aligned}
\frac{d u_{M}}{d \lambda}= & \frac{d \omega}{d \lambda}+\delta \frac{d Q}{d \lambda} \\
\left.\frac{d u_{M}}{d \lambda}\right|_{\lambda=0.5} & =\left[\frac{2 G^{-\alpha}\left(R^{1-\beta}\right)^{-(1-\alpha)} \Omega}{\sigma-1}[\alpha(1-\alpha)(\sigma-1) \sigma V+\alpha Z(R+\sigma(\beta(1+R)(1-\alpha)+\right. \\
& +\alpha-2 R-1))+Z^{2}\left(-(1-\alpha)(\sigma-1)\left(V\left(\alpha \sigma+\frac{0.5}{(\beta-0.5)}\right)+R\left(\sigma\left(1+\alpha^{2}\right)-1\right)\right)\right]+ \\
& \left.+\delta \frac{4}{(1+(R-1) \beta)^{2}} e^{\frac{-\beta \mu_{c} R-\mu_{h}(1-\beta)}{1+\beta(R-1)}} \alpha \beta \sigma R\left(\mu_{c}-\mu_{h}\right)\left(Z^{2}-1\right) V \frac{1-\beta}{2(\beta-0.5)}\right] \times \\
& \frac{\alpha Z R+Z^{2}(\sigma-1)\left(-(1-\alpha) \frac{V}{2(\beta-0.5)}+R\right)+\sigma(\alpha+\beta(1-\alpha)(1+R)-R-1)}{2(\mathrm{~A})}
\end{aligned}
$$

where $V \equiv 2(\beta-0.5)(\beta(1+R)-1), Z \equiv\left(1-T^{1-\sigma}\right) /\left(1+T^{1-\sigma}\right)$ and $\Omega$ as defined in equation (A1).

For the case of $\beta=0.5$ and $R=1$ equation (A6) becomes

$$
\left.\frac{d u_{M}}{d \lambda}\right|_{\substack{\lambda=0.5 \\ R=1 \\ \beta=0.5}}=\frac{2 G^{-\alpha} \Omega}{\sigma-1} \frac{\left[\alpha Z\left(1-2 \sigma+Z^{2}\left(\sigma\left(1+\alpha^{2}\right)-1\right)\right]\right.}{\alpha Z+Z^{2}(\sigma-1)-\sigma}
$$

where $Z$ is as defined in (A6) and $\Omega$ as in (A1); variable For the case of $\beta=1$ equation (A6) turns into

$\left.\frac{d u_{M}}{d \lambda}\right|_{\substack{\lambda=0.5 \\ \beta=1}}=2 G^{-\alpha} \Phi \frac{[Z(1-\sigma(1+\alpha))-\sigma(1-\sigma)(1-\alpha)(1+Z)]}{(1-\sigma)(\sigma-Z+\sigma Z)}$

where $\Phi=\alpha^{\alpha}(1-\alpha)^{1-\alpha}$ and $Z$ as defined as in (A6). Note that $R=1$ since commuting costs have become irrelevant in the absence of commuting. 


\section{A.2 List of variables}

\begin{tabular}{|c|c|}
\hline Variable & Description \\
\hline$M$ & manufacturing good (quantity composite) \\
\hline$m(i)$ & local demand for variety $i$ \\
\hline$m(j)^{*}$ & demand for imported variety $j$ \\
\hline$H_{c}$ & housing demand of non-commuters in the centre (group 1) \\
\hline$H_{c}^{*}$ & housing demand of commuters in the surroundings (group 2) \\
\hline$H_{s}$ & $\begin{array}{l}\text { housing demand of non-commuters in the surroundings (group } \\
\text { 3) }\end{array}$ \\
\hline$H_{s}^{*}$ & housing demand of commuters to the centre (group 4) \\
\hline$Q$ & environmental quality \\
\hline$D$ & environmental damage \\
\hline$w_{M}$ & manufacturing wage \\
\hline$G$ & price index consumption good (for one unit of $M$ ) \\
\hline$p_{m}(i)$ & consumer price of variety $i$ \\
\hline$p_{M}$ & producer (f.o.b.) price of variety $i$ \\
\hline$F \equiv \alpha / \sigma$ & fixed labour input in manufacturing \\
\hline$a_{M} \equiv \rho$ & variable labour input in manufacturing \\
\hline$q_{M}=F \cdot \sigma$ & manufacturing output of a single firm \\
\hline$w_{H}$ & housing wage \\
\hline$p_{H}$ & price of one unit of housing \\
\hline$\lambda$ & share of manufacturing labour in the centre \\
\hline$g_{1}$ & group 1 \\
\hline$g_{2}$ & group 2 \\
\hline$g_{3}$ & group 3 \\
\hline$g_{4}$ & group 4 \\
\hline Y & total income per region \\
\hline$y_{M}$ & per capita income of manufacturing workers \\
\hline$\omega$ & real income in manufacturing \\
\hline$u_{M}$ & per capita utility of manufacturing workers \\
\hline
\end{tabular}




\section{Abstract:}

Mobility in its current shape leads to a range of substantial detrimental environmental impacts. We thus seek to enhance the modelling of transport demand and its environmental effects by developing a spatial Computable General Equilibrium model to evaluate transport and spatial planning instruments. Our model is of the core-periphery type, in which residents are mobile between an urban core and its hinterland. Migration is the result of regional differences in pollution levels, caused by residents' mobility patterns, in housing prices and in the variety of consumption goods. Building on New Economic Geography forces, we explain how urban sprawl affects settlement structures via a circular linkage of spatial environmental quality and mobility patterns. The empirical analysis aims to investigate the potential of using cordon pricing and spatial planning to improve the environment across both regions.

\section{Zum Inhalt:}

Der Verkehr in seiner momentanen Form trägt zu substantiellen negativen Umweltwirkungen bei. Ziel dieser Studie ist daher, die Modellierung der klimarelevanten Verkehrsnachfrage zu verbessern, indem ein räumliches Angewandtes Gleichgewichtsmodell zur Beurteilung von Verkehrs- und Raumplanungspolitik entwickelt wird. Das Modell basiert auf dem KernPeripherie-Modell in dem Bewohner zwischen einem urbanen Zentrum und einer Umlandregion mobil sind. Durch regionale Unterschiede in der vom Verkehr beeinflussten Umweltqualität, in den Wohnpreisen und der Produktvielfalt entsteht Migration zwischen den Regionen. Basierend auf den Kräften der Neuen Ökonomischen Geographie wird erklärt, wie die Zersiedelung über eine zirkuläre Kausalität von räumlicher Umweltqualität und Mobilitätsverhalten die Siedlungsstruktur beeinflusst. In der empirischen Analyse wird das Potential von Cordon Pricing und Raumplanung zur Verbesserung der Umweltqualität in beiden Regionen untersucht. 